\title{
Gravitational slope deformation, not neotectonics: Revisiting the Nordmannvikdalen feature of northern Norway
}

\author{
Thomas F. Redfield' \& Reginald L. Hermanns ${ }^{1,2}$ \\ ${ }^{1}$ Geological Survey of Norway, Post Box 6315 Sluppen, 7491 Trondheim, Norway. \\ ${ }^{2}$ Department of Geology and Mineral Resources Engineering, Norwegian University of Science and Technology, Trondheim, Norway. \\ E-mail corresponding author (T.F. Redfield): tim.redfield@ngu.no
}

A semicontinuous, lobate-to-linear, scarp-like feature slightly less than $1.3 \mathrm{~km}$ long strikes NW-SE across the northeast-facing slope of Nordmannvikdalen in Troms County, northern Norway. Its amplitude undergoes continuous decay from a maximum of slightly more than 1.25 $\mathrm{m}$ in the southeast to about $20-25 \mathrm{~cm}$ in the northwest. This 'Nordmannvikdalen feature' (NVDF) was previously interpreted as the trace of a recently active (e.g., neotectonic) normal fault. However, its greatest possible continuous surface rupture length is geologically constrained to no more than $6 \mathrm{~km}$, and more probably zero. Its scarp length and displacement are incompatible with empirically derived magnitude/length and magnitude/height relationships for seismic surface ruptures. Shallow trenching near the southeastern end of the feature revealed an undeformed soil stratigraphy, a scarp composed entirely of topsoil, and no evidence of erosion typical of post-earthquake degradation or multiple offsets. Reinterpretation of three previously published Ground Penetrating Radar (GPR) profiles favors neither surface breaching nor 'blind' throw.

Deep-seated Gravitational Slope Deformation (DSGSD) occurs at both ends of the NVDF. A plane through its scarp trace matching ca. $45^{\circ}$ NE-dipping bedrock structures interpreted from GPR imaging projects through both DSGSD back-cracks. Low-angle foliation and thrust fabrics permit development of a complex basal failure surface below the NVDF. However, lower slope deformation typical of DSGSDs is not apparent and offset in the subsurface below the scarp cannot be unambiguously resolved by the GPR data. Signs of surface soil deformation, by freezethaw creep or other processes typical of periglacial environments, are rampant. Many of the NVDF's scarp morphologies are consistent with relict permafrost landforms such as short- and long-wavelength solifluction/gelifluction lobes and sheets, and appear controlled to a surprising degree by the along-strike change in dip of the underlying bedrock surface. We present one possible model conceptualizing how slope-parallel surface lineaments might form in mobilized permafrost soils. Nevertheless, a purely superficial origin of the NVDF cannot easily explain the spatial coincidence of the lineament with the trace of a structural plane describing both DSGSDs, and is therefore also incomplete.

The NVDF is a unique landform which we do not fully understand. However, being certain that it was not formed by Holocene seismic surface rupture, we propose its status should be downgraded to " $E$ (Very unlikely to be neotectonics)". Because Norway's paleoseismic and pre-instrument seismic records are poorly controlled, converting yet another onshore neotectonic fault commensurate with $\mathrm{Mw}>5.8$ surface rupture to the product of some sort of gravitational instability has relevance for better understanding medium-large earthquake recurrence intervals in Fennoscandia.

Keywords: neotectonic, fault, Scandinavia, Norway, permafrost, solifluction, gelifluction, lineament, DSGSD (Deep-seated Gravitational Slope Deformation), slope stability, soil creep, Little Ice Age, Arctic geomorphology

Received 1. May 2016 / Accepted 1. September 2016 / Published online 29. November 2016

\section{Introduction}

To date, several candidates for postglacial faults in Norway have been proposed (see review by Olesen et al., 2013). These include the Stuoragurra fault (Olesen, 1988;
Muir Wood, 1989), certain elements of the Båsmoen fault (Olesen et al., 1994), the Berill fault (Anda et al., 2002), and the Nordmannvikdalen fault/feature (NVDF; Bakken, 1983; Tolgensbakk \& Sollid, 1988; Dehls et al., 2000). Of these, only the Stuoragurra fault can be

Redfield, T.F. \& Hermanns, R.L. 2016: Gravitational slope deformation, not neotectonics: Revisiting the Nordmannvikdalen feature of northern Norway. Norwegian Journal of Geology 96, 245-273. http://dx.doi.org/10.17850/njg96-3-05. 

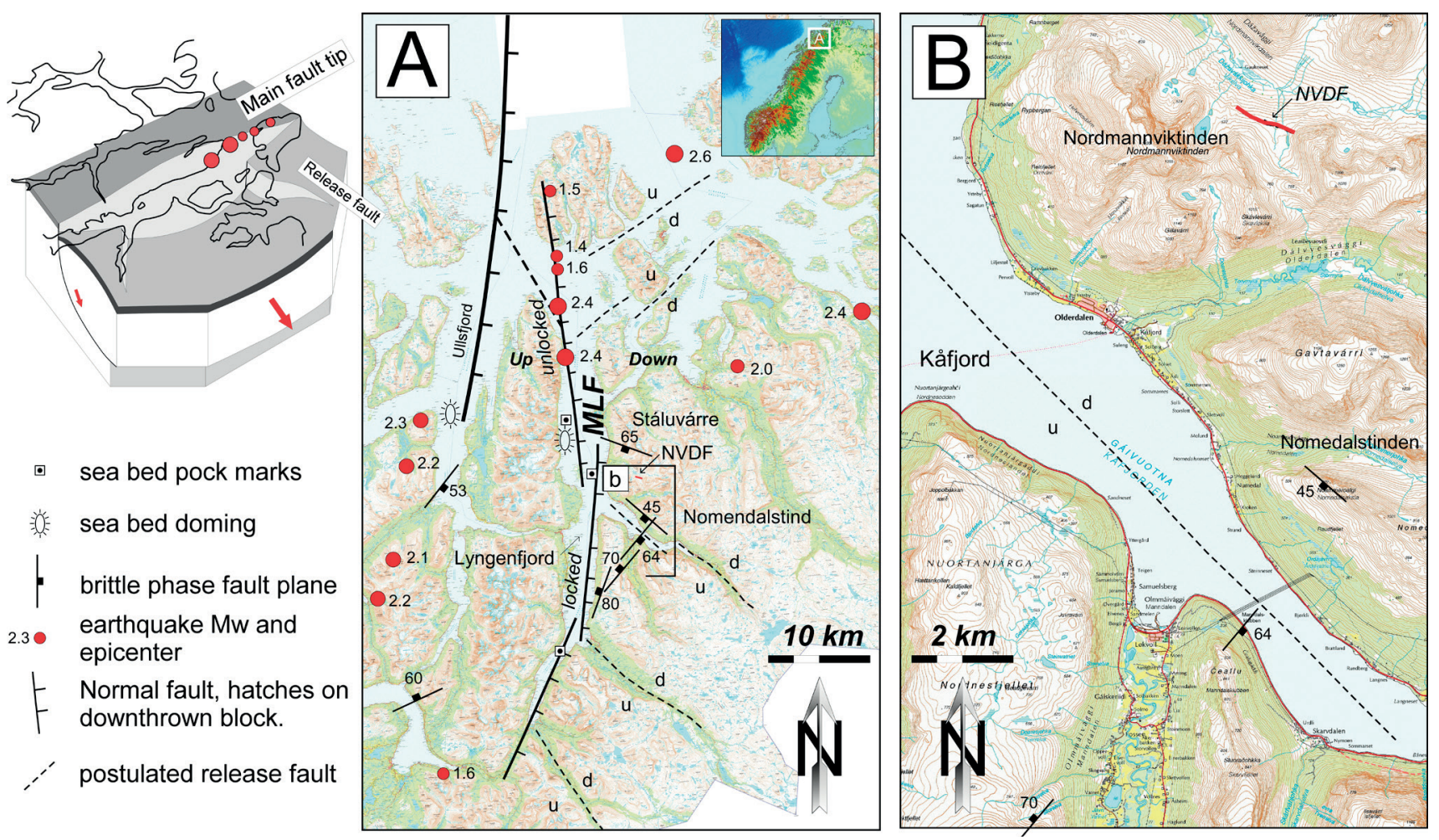

Figure 1. Location maps showing the Nordmannvikdalen feature (NVDF) with respect to northern Norway and geological elements of the greater Kåfjord-Lyngen Alps area. Block diagram at left illustrates a 'release fault' model after Destro (1995), very similar to the tectonic model proposed by Osmundsen et al. (2009). Panel (A) shows earthquake epicenters (NORSAR 1970-2015 database), sea-floor pockmarks and seafloor doming (Hovland \& Judd, 1988; Plassen \& Vorren, 2003), brittle-phase fault outcrops known in the region, and the Main Lyngen Fault (MLF) as interpreted from Satellite Interferometry land motion data, landscape contrasts, and earthquake data (see Osmundsen et al., 2009). Fault outcrop symbols depict localities where post-Caledonian brittle-phase fault rocks have been identified. The heavy fault line symbol in Ullsfjord is interpreted to be part of a Barents Sea fault system (Sigmond, 1992). Dashed fault lines labels 'd' and 'u' refer to hanging wall footwall predictions of the release fault model. Panel (B) shows location and observed length of the NVDF. Dashed fault line in Kåfjord parallel to known faults at Stáluvárre and Nomedalstinden is a conceptual interpretation based on the release fault model

definitively shown to have ruptured, in reverse mode, during the Holocene (Olesen, 1988; Muir Wood, 1989; Olesen et al., 1994; Dehls et al., 2000). At least one of the Båsmoen fault planes has been reported as having possibly been postglacially reactivated in reverse sense by a maximum of 30 to $40 \mathrm{~cm}$ (Olesen et al., 2000). An onsite inspection during 2016 did not confirm this interpretation. Recent fieldwork (Krieger et al., 2013; Schleier et al., 2016) suggests that the Berill fault, alive and well during Caledonian collapse, was partially reactivated at a later stage as a normal fault or a Deepseated Gravitational Slope Deformation (DSGSD). However, trenching of the valley fill sediments along the fault trace did not document offset strata, liquefaction structures, or other evidence indicative of Holocene earthquake activity (Schleier et al., 2016).

The NVDF, then, is the sole remaining candidate for onshore postglacial tensile (normal) tectonic reactivation within the Norwegian Escarpment Zone (Figs. 1, 2). Furthermore, it is located in a region where a variety of observations point strongly towards Cenozoic, and probably Quaternary, tectonic activity (Fig. 1; see
Osmundsen et al., 2009, 2010). Because earthquakes in onshore Norway tend to be normal to normal-oblique (Hicks et al., 2000; Keiding et al., 2015), repeat intervals for medium-large $\left(M_{w} \geq 6.0\right)$ events are uncertain in Scandinavia (e.g., Bungum et al., 2005), and such tremors are known to cause landsliding (see Keefer, 1984), its importance to Norwegian geology becomes that much the greater. Yet since 2000, no new work on the NVDF has been formally reported (e.g., Olesen et al., 2013).

A field party from the Geological Survey of Norway accessed the locality during the summer of 2011. Our visit was initiated by the desire to obtain samples from the fault for cosmogenic or radiocarbon dating, plus the collection of sufficient geological data to place those samples into context such that we could quantitatively constrain the age of faulting. However, upon inspection of nearby bedrock outcrops and a shallow excavation into the scarp itself, we began to assume the uncomfortable condition of doubt.

"Is it a fault scarp, or isn't it?" That was our question. 


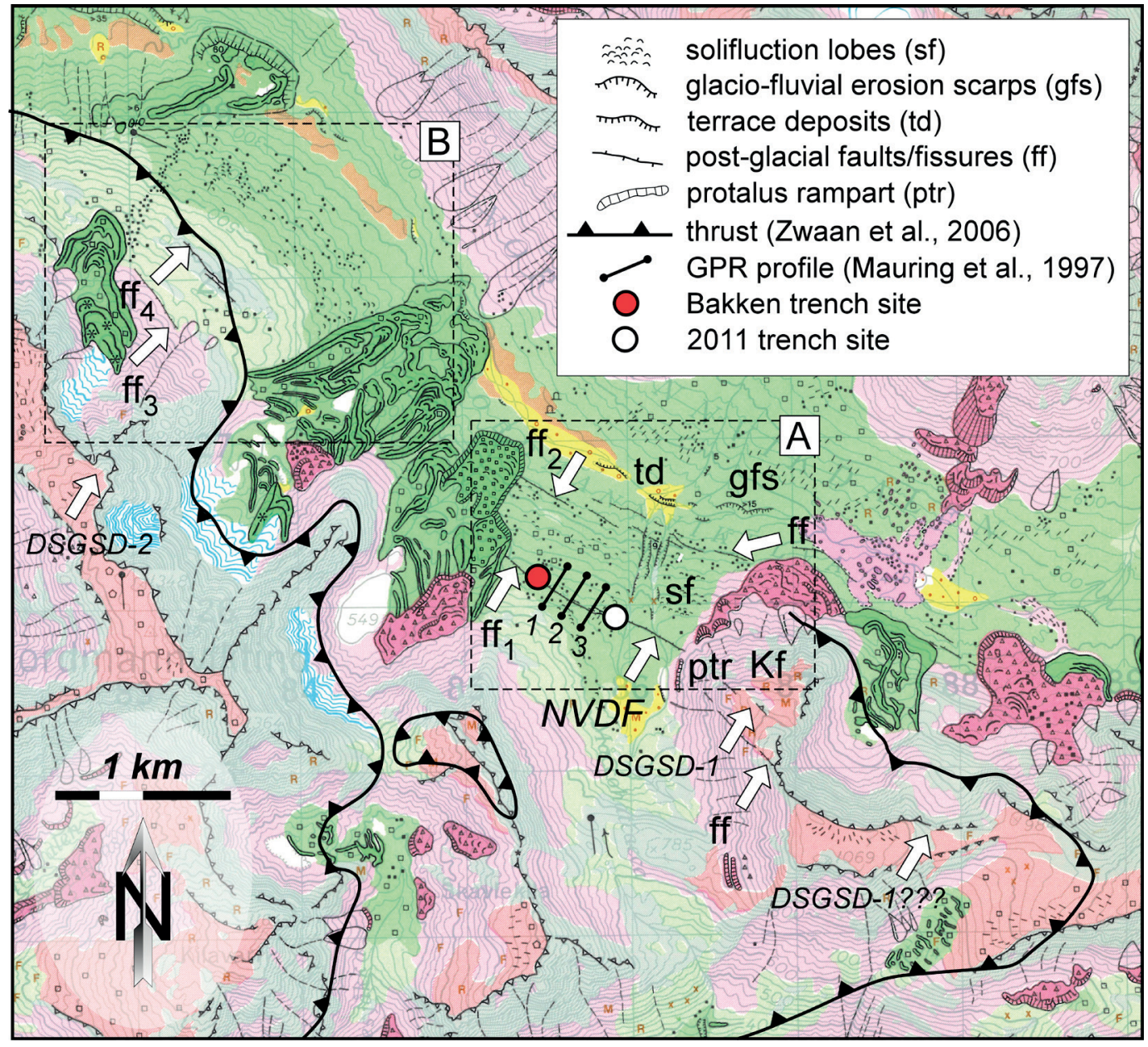

Figure 2. Reproduction of a portion of the Quaternary geological map of Tolgensbakk \& Sollid (1988) covering the area of the Nordmannvikdalen feature (NVDF). The NVDF was categorized and mapped as being one of a set of 'postglacial fault/fissures' (ff). White arrows point to other ff structures identified in the vicinity. Thrust faults after Zwaan et al. (2006). Also shown are the three existing Ground Penetrating Radar profile locations (GPR; Mauring et al., 1997) and the locations of the trenches dug by the 2011 NGU field party and A. Bakken in or around 1981-1983. DSGSD stands for Deep-seated Gravitational Slope Deformation. Kf locates Kistefjellet. Inset boxes A and B refer to smaller scale views shown in Fig. 16

\section{Something is rotten in the valley of Nordmann}

Earthquake magnitude vs. fault rupture theory and an initial set of field observations fueled our worry. A shallow, opportunistically excavated trench revealed a continuous soil stratigraphy across the scarp. The scarp exhibits lobate geometries that appear more typical of mobilized soil than either hard or soft tectonic linkage between fault segments. Empirical data that relate earthquake moment magnitude $\left(\mathrm{M}_{\mathrm{w}}\right)$ to parameters of fault rupture suggest the NVDF's ca. 1 m maximum displacement is by an order of magnitude incompatible with its observable length (Wells \& Coppersmith, 1994). Whilst Deep-seated Gravitational Slope Deformation (DSGSD) objects lie directly along its strike at either end, geological data justifying an extension of the NVDF's surface rupture length to greater than $6 \mathrm{~km}$ have not been found. Yet its well-preserved nature in a recently deglaciated area rich with landforms indicative of mobilized soil
(Tolgensbakk \& Sollid, 1988) suggests that the NVDF formed very recently. As such, it is difficult to hypothesize that it is the product of many small earthquakes distributed over a longer period of time.

These issues spurred us to re-evaluate the status of the NVDF as a neotectonic fault. In this contribution we utilize modern digital images to impose some geometric constraints on the NVDF, especially including the maximum possible length of a single rupture event. We document the topographic displacement gradient of the scarp, which we then test against empirically derived fault scaling relationships (Wells \& Coppersmith, 1994). We describe observations from our own shallow excavation and interpret a sketch of a trench dug by Bakken (1983). Lastly, we extend the Ground Penetrating Radar (GPR) surveys of Mauring et al. $(1997,1998)$ by developing and interpreting a GPR reflector stratigraphy. After assessing our data, we suggest that the NVDF is not of tectonic origin, and propose its rating (Muir Wood, 1993; Fenton 1994) should be downgraded to "(E) Very 

unlikely to be neotectonics." We close by offering alterna- Geological background
tive hypotheses for the lineament's existence.

The 1:50,000 bedrock map of Kåfjord (Zwaan et al., 2006) depicts the quadrangle as floored entirely by Caledonide
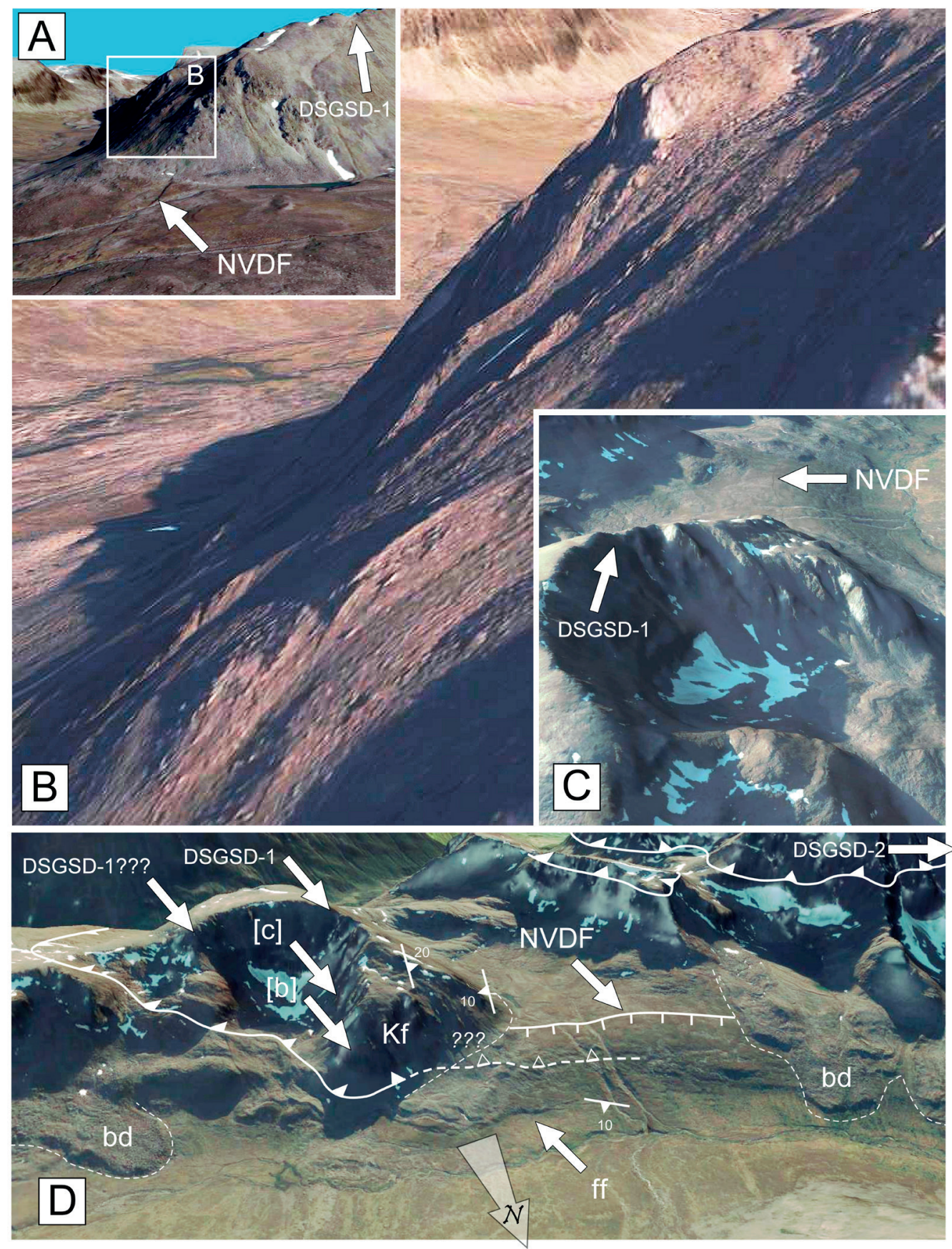

Figure 3. Images of Kistefjellet (Kf). Subfigure (A) shows an overview from above the Nordmannvikdalen feature (NVDF), looking to the southeast. White box shows the location of subfigure (B). (B) highlights a set of generally NE-dipping structures, some apparently exhibiting cross-cutting relationships. (C) shows an overview of the Kistefjellet cirque. Note the strong, NE-dipping planar structures. The tip of the uppermost white arrow points to the NVDF scarp in the distance. DSGSD stands for Deep-seated Gravitational Slope Deformation. The inner limit to DSGSD-1 was mapped by Tolgensbakk \& Sollid (1988) as a postglacial fault/fissure (ff). (D) shows an overview of the NVDF and Kistefjellet from the north. Foliation and solid thrust symbols after Zwaan et al. (2006); the leftmost ('backsliding') thrust fault is purely hypothetical where dashed, and its actual dip is unknown. Approximate locations of rock structures shown in (B) and (C) are shown by white arrows. 'bd' refers to boulder deposit. Symbol ??? refers to the debatable lineation discussed in the text and shown in Fig. 4. Note shadowed, NVDF-parallel (ff) lineaments near the base of the slope (see Fig. 2). Images modified from www.norgei3d.no. Images of the Kistefjellet (Kf) Deep-seated Gravitational Slope Deformation (DSGSD-1). Subfigure (E) provides an overview. Dashed white line 
thrust sheets. Crystalline basement rocks do not crop out within its limits. Much of the map is dominated by hornblende biotite schists of the Upper Allochthon's Kåfjord Nappe (op. cit.).
Little site-specific bedrock geological information exists adjacent to the NVDF. Bedrock exposures at either end of its trace are of Kåjord Nappe schist perturbed by gentle to open folds. Structural data are sparse. Zwaan et al. (2006) mapped a series of shallow-plunging fold axes
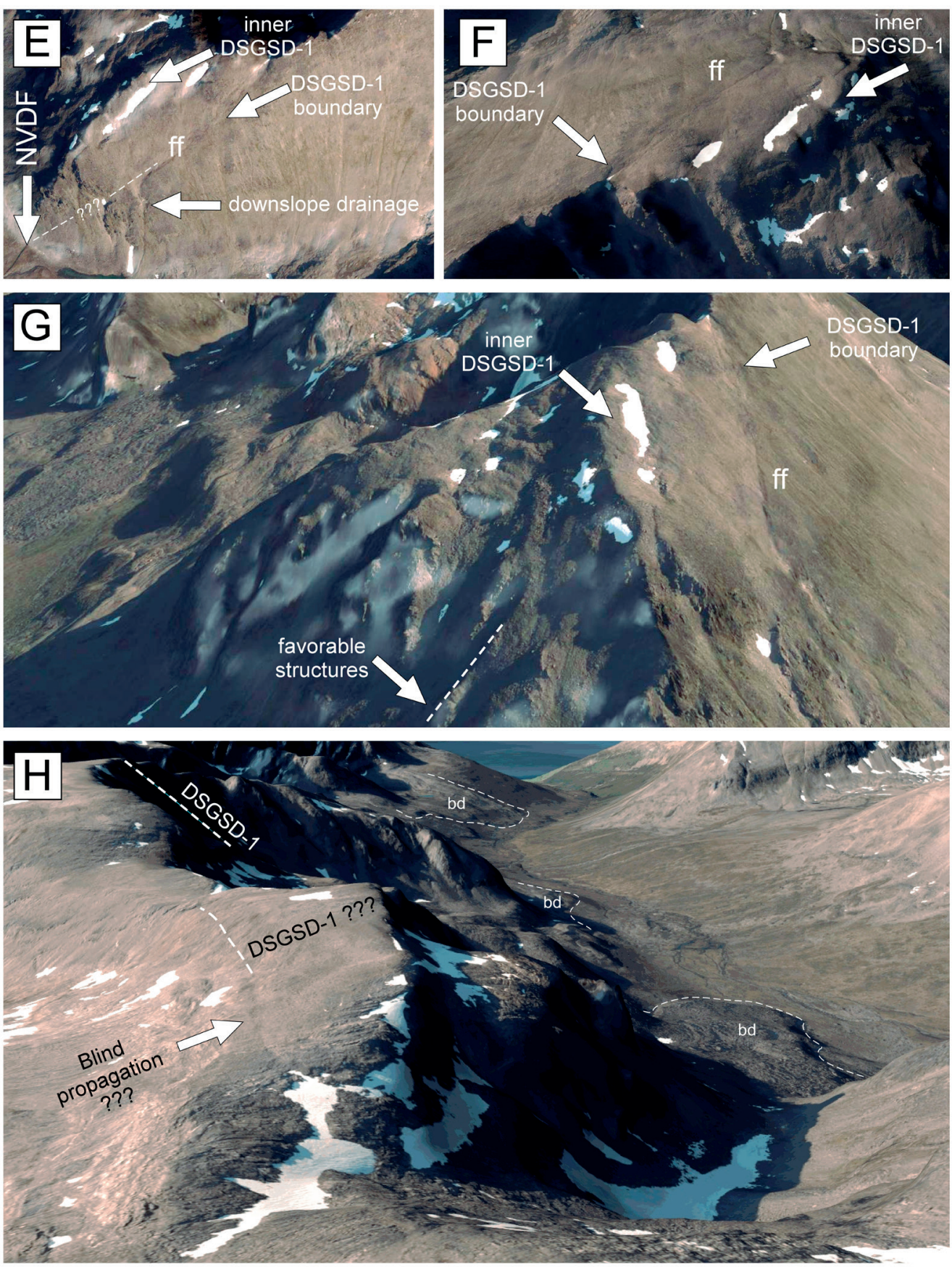

represents the Nordmannvikdalen feature (NVDF) projected to the southeast using a $45^{\circ} \mathrm{NE}$ dip (see text). Note the coincidence with the postglacial fault/fissure (ff) mapped by Tolgensbakk \& Sollid (1988) and the DSGSD-1 inner cutoff. (E) provides a view looking southeast and showing details of the subparallel inner and outer DSGSD-1 sectors. (F) provides a view looking northwest illustrating slope-parallel planar structures dipping on the order of $45^{\circ}-50^{\circ}$ to the northeast. Note how the pervasive nature of these structures controlled cirque erosion. $(G)$ shows Kistefjellet, looking to the southeast. Note favorably dipping structures and the ff lineament of the DSGSD-1 inner boundary. (H) shows the southeastern side of the Kistefjellet cirque, looking to the northwest. The surface lineament marked DSGSD-1??? is very subtle, indicating the underlying controlling structure is underdeveloped. DSGSD-1??? is not directly on-strike with DSGSD-1 or the NVDF projection. Note the contrast between plentiful boulder deposits (bd) on the southern side of Nordmannvikdalen, and few, if any, on its south-facing northern flank. Images modified from www.norgei3d.no. 
trending roughly NNW-SSE and a west-dipping, very low-angle, minor thrust fault or crush zone within the Kåfjord Nappe (Figs. 2, 3D). This they interpreted as a possible late thrusting stage "back-sliding plane", perhaps implying some sort of relationship with extensional collapse. On their map the thrust trace is terminated near the base of Kistefjellet at an elevation of about $500 \mathrm{~m}$ ASL, and does not extend beneath the NVDF.

Modern Digital Elevation Model (DEM)-draped imagery of the Kistefjellet cirque provides an overview of the bedrock structure (Fig. 3). The north face of Kistefjellet appears to host pervasive, closely spaced, moderate- to steeply-dipping, open to gently folded, hillslope-parallel or subparallel structural planes. Somewhat at odds with nearby $\mathrm{N}-\mathrm{S}$-striking, gently dipping cleavages recorded by Zwaan et al. (2006), the planes appear to dip generally $\mathrm{N}$ to NE (Fig. 3.1B-D).

Brittle normal faults are known to cross-cut the schists of the Kåjord Nappe in the Nordmannvikdalen area (Fig. 1). Many appear to have controlled the evolution of local rock-slope instabilities and avalanche failure planes (Osmundsen et al., 2009, 2010; Henderson et al., 2011; Bunkholt et al., 2013). One nearby SW-dipping fault striking subparallel to the NVDF crops out as part of a DSGSD on the southern flank of Stáluvárre Mountain. Replete with cataclasite, post-Caledonian, and clearly normal, it lends credence to the hypothesis that some of the apparently north-dipping fabrics of Kistefjellet may also be tectonic fault planes (Fig. 3E-H).

\section{The Nordmannvikdalen Fault/Feature (NVDF)}

Initially described as a 'possible late glacial fault' in the final pages of a University of Oslo MS thesis (Bakken, 1983), the NVDF was presented as a 'postglacial fault or fissure' on the 1:50,000 Quaternary Geology Map of Kåfjord by Tolgensbakk \& Sollid (1988; see Fig. 2). Accurate, precise, and extremely well crafted, the map (op. cit.) was
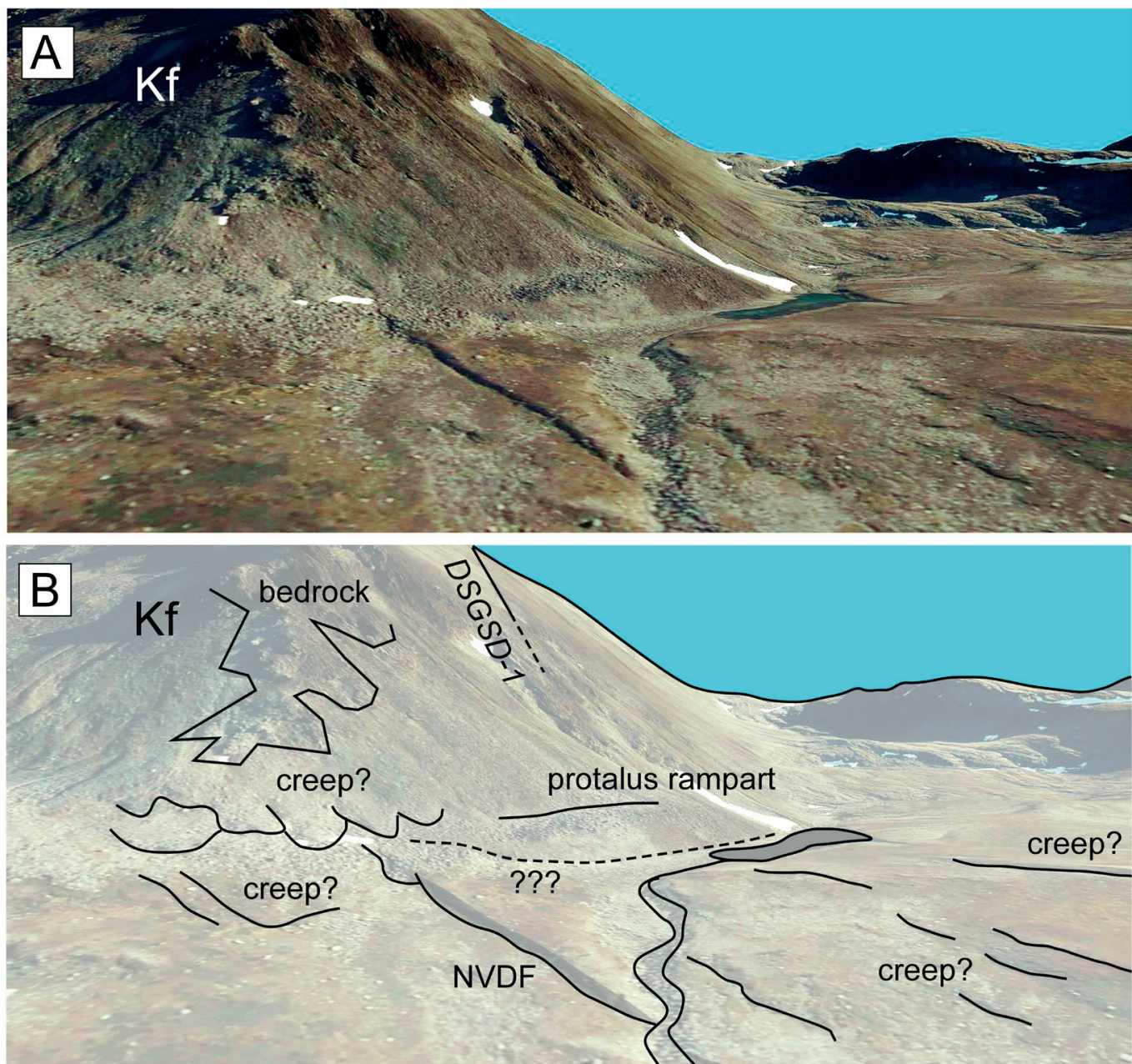

Figure 4. Image and interpretation of the termination of the Nordmannvikdalen feature (NVDF) at its southeastern end. At this locality the NVDF scarp (shadowed) is a little more than $1 \mathrm{~m}$ high. (A) shows an overview of the NW-facing flank of Kistefjellet (Kf). (B) shows one interpretation of possible landform relationships. Protalus rampart as mapped by Tolgensbak \& Sollid (1988). Images modified from www. norgei3d.no. 

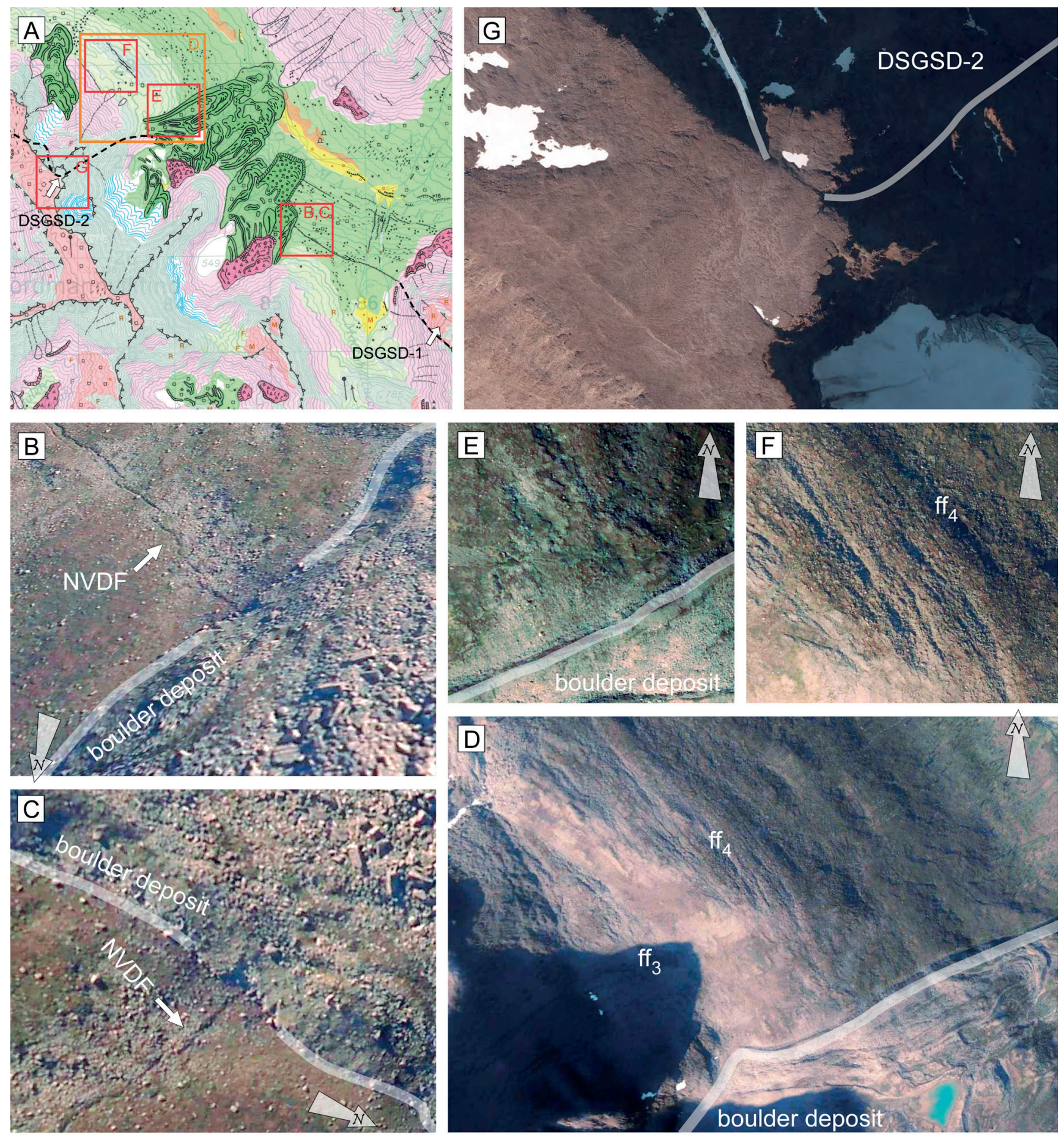

Figure 5. The northeastern end of the Nordmannvikdalen feature (NVDF). Dashed black line indicates the surface trace of a plane parallel to the NVDF and dipping $45^{\circ}$ to the northeast (see main text). Subfigures (A) and (B) show the termination of the feature by, at, or under the southeastern edge of the southeast boulder deposit (Fig. 2, box A). At this locality the NVDF scarp (shadowed feature) is less than $25 \mathrm{~cm}$ high. Subfigures (C) and (D) detail the locality where the along-strike continuation of a vertically dipping NVDF should exit the northwestern edge of the northwest boulder deposit. (E) shows an enlarged view of fanning, discontinuous structures mapped as postglacial fault/fissure (ff4) by Tolgensbakk \& Sollid (1988; see Fig. 2). The semicontinuous NVDF trace of (A-B) is utterly absent. (F) shows the back-crack of an unstable rock compartment near the summit of Nordmannviktinden. The ca. $45^{\circ}$ projection of the NVDF (dashed black line) cuts through the rock back-crack of the body labeled DSGSD-2. Images modified from www.norgei3d.no.

the product of an extended field campaign by Jon Tolgensbakk, Johan Sollid, and several coworkers during the 1980s. At that time, the NVDF was interpreted as a postglacial fault because "it was very straight for more than one $\mathrm{km}$, clearly visible at the surface and passing an area with thick surficial deposits, probably till. Therefore it would most probably be younger than the till. The line could also be followed continuously into an area with bedrock at the surface. So we were all quite convinced that this could be interpreted as a postglacial fault line." (L. Sørbel, pers. comm., 2016). 
Field studies by Mauring et al. $(1997,1998)$ and Dehls et al. (2000) also concluded the feature was a neotectonic offset, its scarp formed during normal-sense reactivation of a pre-existing fault of possibly reverse character. Dehls et al. (2000) based their interpretation on geomorphic observations, local geology, and results from the three-profile GPR study by Mauring et al. $(1997,1998)$. Noting that the up-dip extrapolation of certain NE-dipping GPR reflectors could be projected into the similarly dipping NVDF scarp, Mauring et al. (op. cit.) suggested that they likely represented tectonic- or gravitationally driven fault planes that were active during Holocene time. However, Dehls et al. (2000) subsequently argued against a gravitational mechanism. Applying existing nomenclature (Muir Wood, 1993; Fenton, 1994), Olesen et al. (2004) graded the NVDF as "(A) Almost certainly neotectonics."

\section{The feature}

The NVDF is located on the north-facing slope of Nordmannvikdalen at a mean altitude of about $540 \mathrm{~m}$ ASL
(Fig. 2). It comprises a semicontinuous to discontinuous, linear to lobate series of slope breaks in vegetated soil that collectively define a scarp-like trace nearly $1.3 \mathrm{~km}$ long. Individual scarp components range between a few tens and several hundred meters in extent. The map trace has an overall strike of roughly $285^{\circ}-295^{\circ}$ and the scarp face dips circa $30^{\circ}$ to $45^{\circ}$. In the field the scarp height was observed to gradually and consistently decrease from a little more than $1 \mathrm{~m}$ at its southeastern end (Fig. 4) to less than $20-25 \mathrm{~cm}$ in the northwest (Fig. 5). To the southeast the NVDF disappears into a suite of Holocene/Recent landforms at the base of a bedrock outcrop (Fig. 4). Noting a prominent gulley on the northwestern flank of Kiestefjellet, Mauring et al. (1998) and Olesen \& Dehls (1998) hinted that the NVDF might continue into the bedrock exposures. In a later publication, Dehls et al. (2000) stated that the eastern end of the NVDF "terminates against the foot of a mountain." At its northwestern end (Fig. 5) the greatly diminished NVDF scarp is obscured by a boulder deposit interpreted as either a rock-glacier (Tolgensbakk \& Sollid, 1988) or a rock-avalanche deposit (Jarman, 2009).
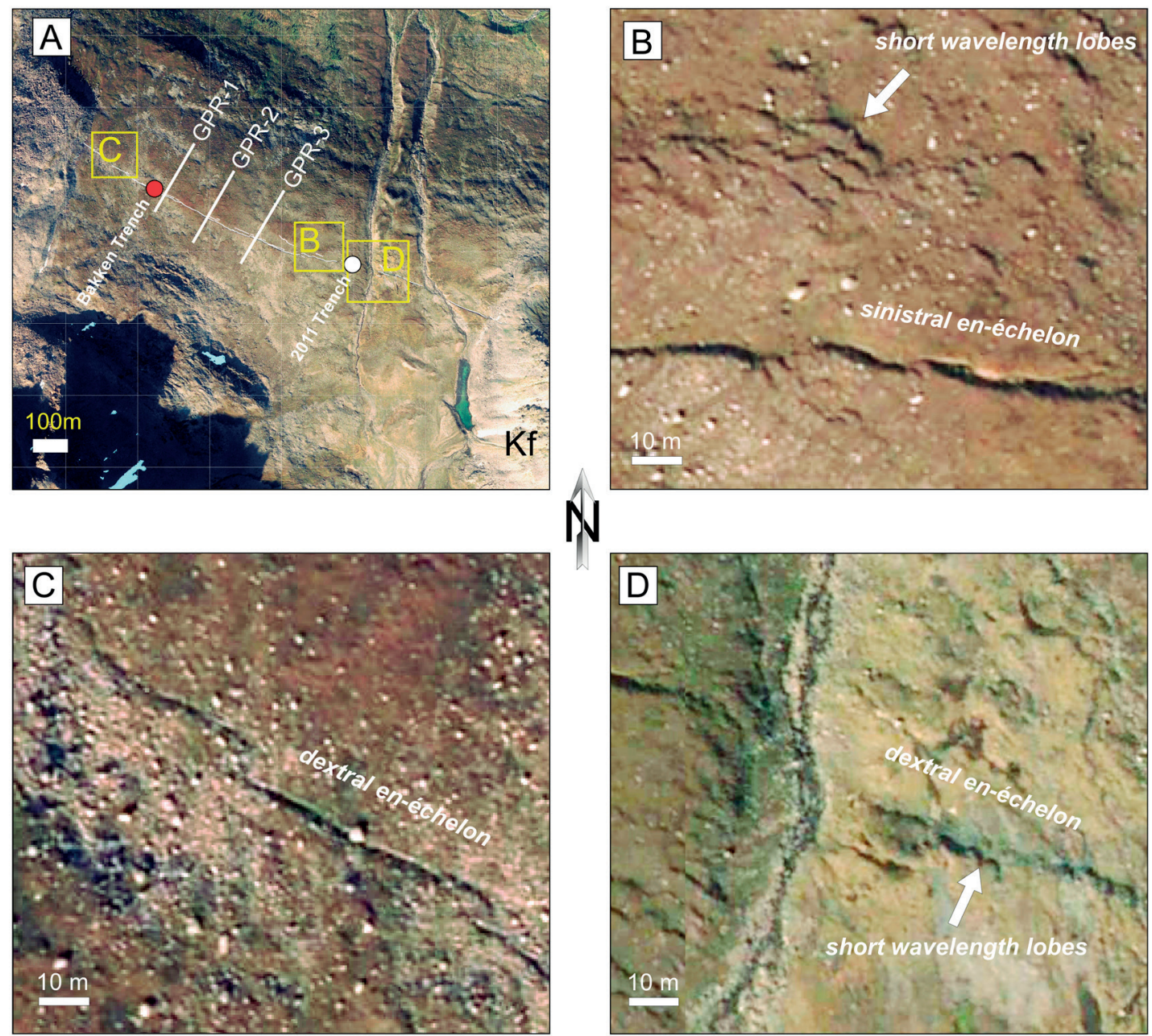

Figure 6. The Nordmannvikdalen feature (NVDF) enjoys a variety of segment linkages and styles, including both sinistral (B) and dextral (C) en-échelon patterns. The white arrow in (B) highlights a series of smaller lobes immediately below the feature. (D) shows an apparent dextral step across the stream-bed, and what appear to be short-wavelength, convex down-slope lobes adorning the NVDF scarp. GPR stands for Ground Penetrating Radar profiles, relocated after Mauring et al. (1997). Location of the Bakken trench was approximated using clues gleaned from Bakken (1983). Kf refers to Kistefjellet. Images modified from www.norgei3d.no. 


\section{The scarp}

The NVDF comprises a set of subscarps. The individual segments do not display a consistent pattern of linkage. Both sinistral and dextral en échelon segmentation is observed (Fig 6). Segment branching adheres to a variety of patterns (Fig. 7). Open tension cracks were not observed in the field. Rather, scarp-parallel drainage channels end abruptly at sediment-filled, sinkhole-like features (Fig. 8). Many scarp segments display longwavelength (e.g., 10+ meters) downslope convexity (Fig. 7). Shorter wavelength, convex-downslope lobes adorn the scarp locally (Fig. 6C), and in many places also the hillside above and below it (Figs. 6B-C, 7C, 9B). Present on the map of Tolgensbakk \& Sollid (1988), these and similar lobes have been interpreted as solifluction features (op. cit.).

Topographic cross-sections extracted from the Statens Kartverks $25 \mathrm{~m}$ resolution DEM and oriented at a high angle to the generalized strike of the NVDF indicate that for much of its length the scarp is adjacent to a pronounced break in hillside slope (Fig. 10). Near its southeastern end, the slope azimuth above the feature, as defined by the skier's fall line, is also partly created by the rock buttress of Kistefjellet itself and therefore somewhat offset from the profile. Nevertheless, it is clear that for most of its length the slope above the NVDF becomes progressively steeper from SE to NW whilst the slope angle immediately below the feature remains relatively constant. As an example, our rough measure of the relative slope difference (expressed in graphical units as opposed to true angles) from above-slope to below-slope changes along strike by nearly an order of magnitude.

\section{Theories of relativity}

Constructing a chronology for the individual landforms at the base of Kistefjellet is not facile. A protalus rampart landform was mapped by Tolgensbak \& Sollid (1988) just upslope from the southeastern end of the NVDF (Fig. 2). On their map the rampart does not intersect the NVDF.
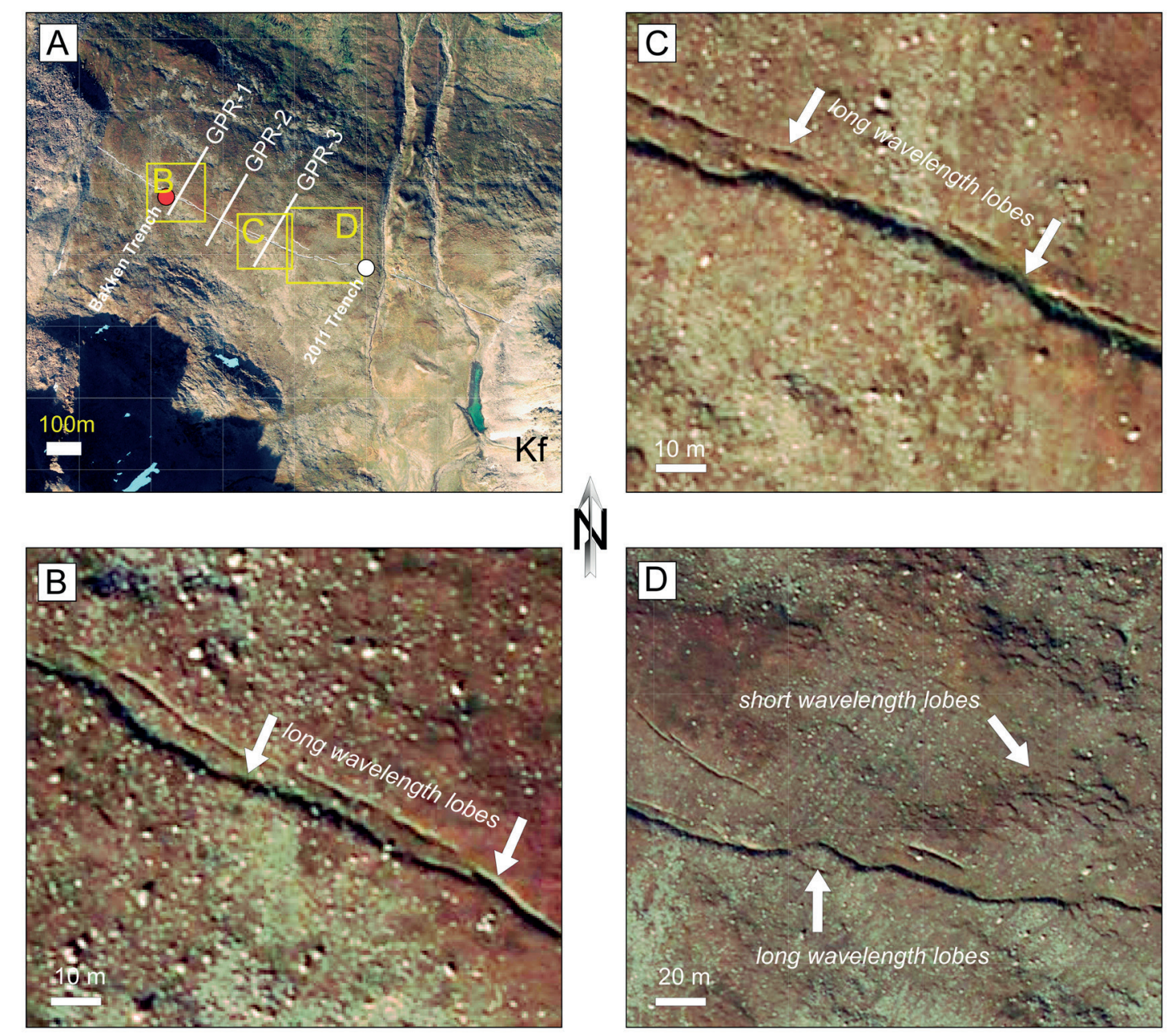

\section{N}

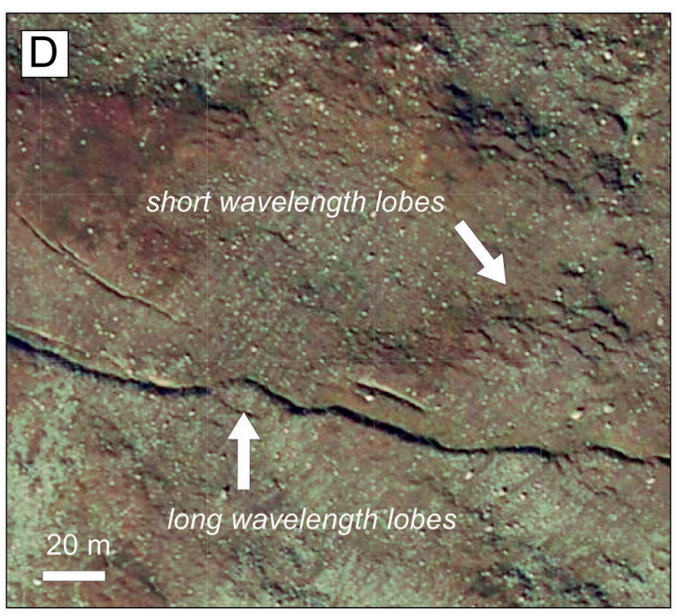

Figure 7. The Nordmannvikdalen feature (NVDF) scarp also exhibits longer-wavelength convex-towards-the-downslope-side lobes and branches in both parallel and diverging modes $(B, C)$. All three images show longer-wavelength downslope convexity. Branches are not tension cracks (see Fig. 6B). GPR stands for Ground Penetrating Radar profiles, relocated after Mauring et al. (1997). Location of the Bakken trench was approximated using clues gleaned from Bakken (1983). Kf refers to Kistefjellet. Images modified from www.norgei3d.no. 

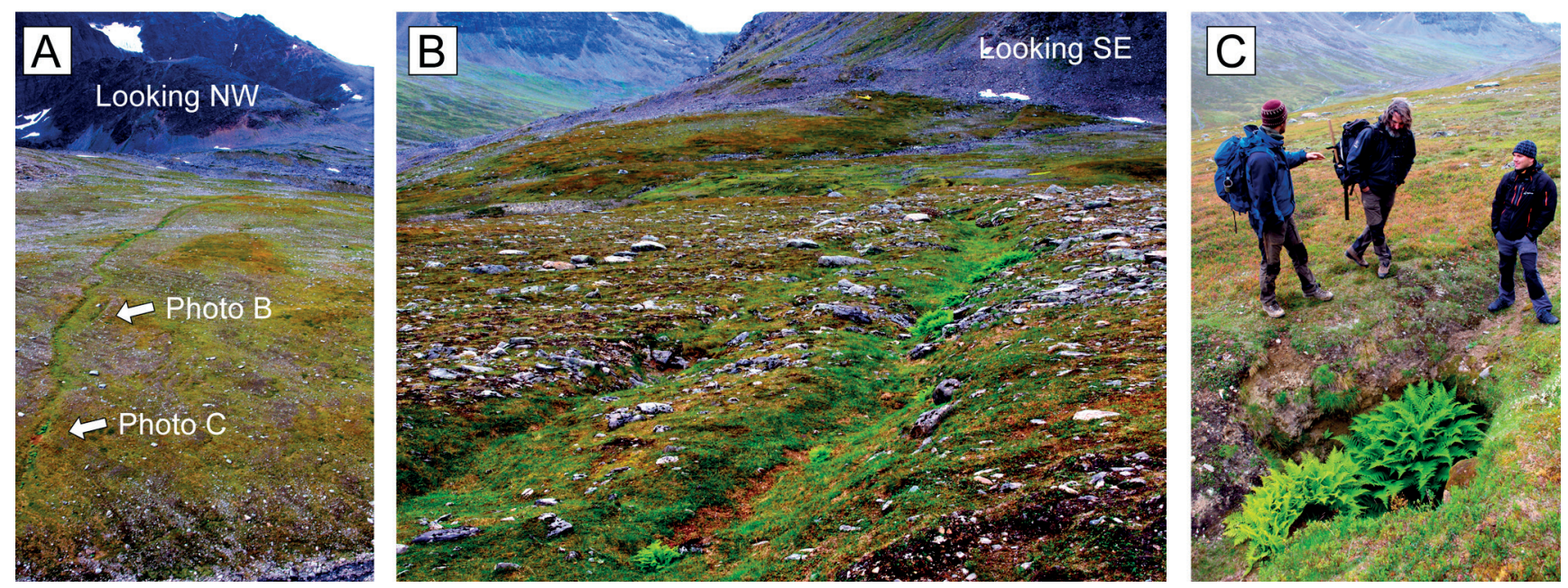

Figure 8. Subfigure (A) shows the Nordmannvikdalen feature (NVDF) from the southeast. Subfigure (B): Field photograph showing absence of tension cracks near Site (A) of Fig. 7. Subfigure (C): Field photograph showing evidence for internal drainage near site of Fig. $7 B$.

Modern topographically draped color photographs (www.norgei3d.no) hint that a linear feature, below and adjacent to the rampart, might extend downslope of the NVDF (Fig. 4). Similarly, lobate talus bodies just upslope of the NVDF scarp hint towards an overprinting relationship. However, we readily admit such observations are debatable. The relative age of the NVDF scarp with respect to these landforms is opaque.
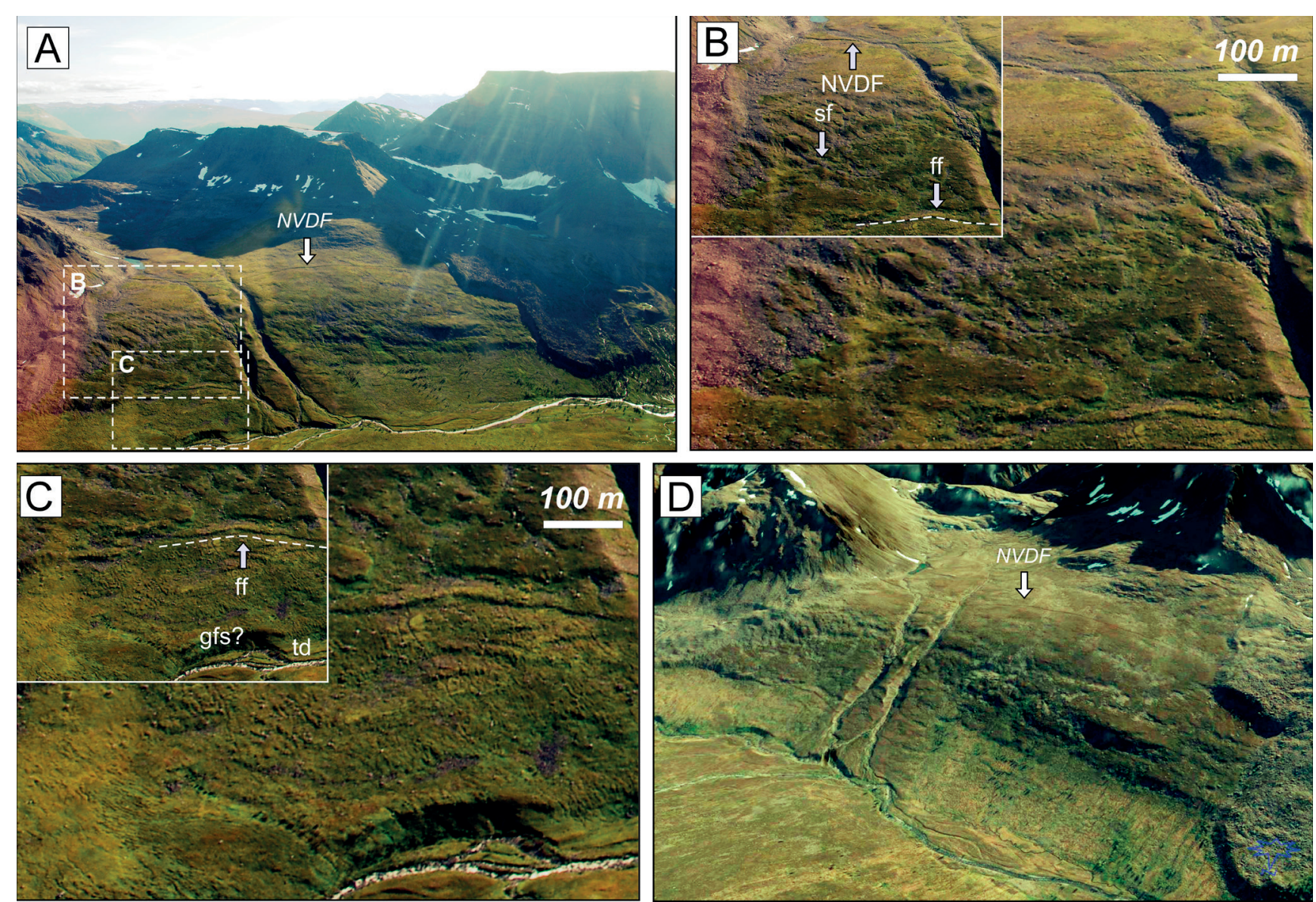

Figure 9. Overview of slope morphologies below the Nordmannvikdalen feature (NVDF). Subfigure (A): Aerial photograph showing locations of close-up images in (B) and (C). Subfigures $(B)$ and $(C)$ show a series of linear, semilinear, and lobate soil structures near the foot of the lower slope, yet well above the terrace deposits $(t d)$. Subfigure $(D)$ : Post-processed image modified from www.norgei3D.no showing lobes and linear deformation traces on the lower slopes below the NVDF. Some of the solifluction lobes (sf) mapped by Tolgensbakk \& Sollid (1988; see Fig. 2) can be seen on the slopes below the southeastern and northwestern ends of the NVDF (see B). 

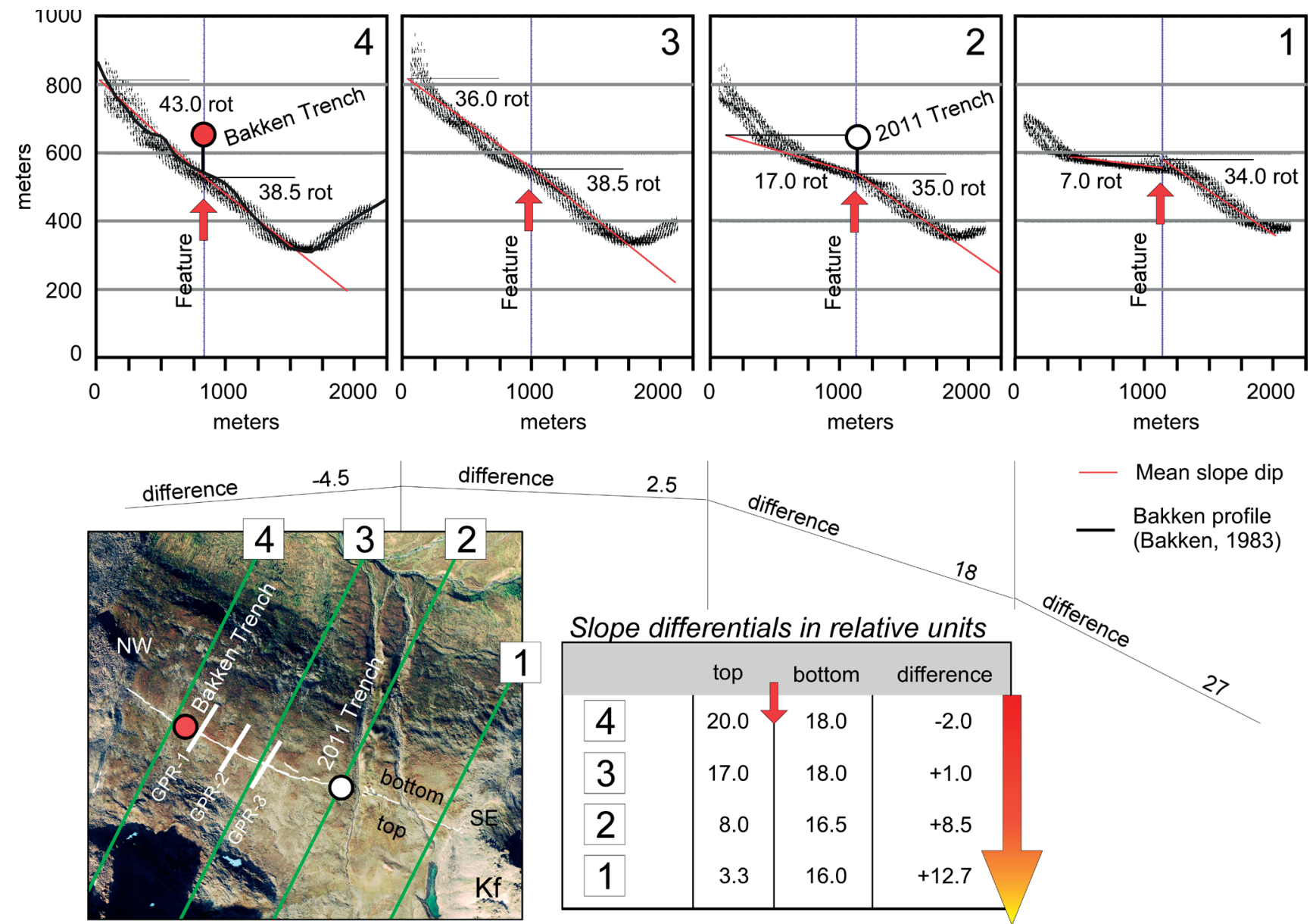

- Mean slope dip

Bakken profile

(Bakken, 1983)

Figure 10. Topographic cross-sections drawn perpendicular to the Nordmannvikdalen feature (NVDF) extracted from the $25 \mathrm{~m}$ Digital Elevation Model (DEM) of Statens Kartverk. On each graph the location of the NVDF is shown by a red arrow. Red lines approximate slope steepness immediately above and below the feature; 'rot' refers to the relative rotation from the horizontal (note that true rotation at 1:1 scale is less). The slope below the feature remains of similar steepness along the entire trace, but the slope above becomes gradually shallower to the northwest. The change in slope (expressed as the relative difference between the upper 'top' and lower 'bottom' slopes) is shown in the chart. GPR stands for Ground Penetrating Radar profiles, relocated after Mauring et al. (1997). Location of the Bakken trench was approximated using clues gleaned from Bakken (1983). Kf refers to Kistefjellet. Image modified from www.norgei3d.no.

The situation is no better at the northwestern end. If the NVDF is a fault trace resulting from ground rupture, the boulder deposit must overlie the NW continuation of its scarp and therefore be younger. However, if the scarp represents a soil displacement formed above a subsurface rupture (e.g., a fault monocline), or is not related to a fault offset at all (e.g., surface soil creep), it can predate, postdate, or be contemporaneous with the boulder deposit.

\section{Extension as a DSGSD to the southeast}

Our own short search of Kistefjellet's lower slope failed to turn up brittle fault rocks or lineated fault planes such as those on Stáluvárre mountain (Fig. 1; Osmundsen et al., 2009), and we are not aware of any literature reporting such from the Nordmannvikdalen locality. However, Tolgensbakk \& Sollid (1988) did map a postglacial fault/fissure running up the NW flank of Kistefjellet (ff in Fig. 2).
An inverse three-point solution (Fienan, 2005) employing a dip of $45^{\circ}$ along the NVDF strike closely approximates both the NVDF and the postglacial fault/fissure traces. DEM-draped images indicate it probably delineates the outer boundary of a relatively large (ca. 10E + 06 million $\mathrm{m}^{3}$ ) slope instability labeled DSGSD-1 (Figs. 2,3.1-3.2).

DSGSD-1 appears to be cross-cutting the entirety of Kistefjellet. Voluminous boulder deposits below the cirque and 'missing' bodies of rock at its rim testify to previous large-volume catastrophic or semicatastrophic failure(s). A faint linear trace in the summit blockfield just southeast of the cirque summit may betray a presentday propagation of gravitational deformation at depth (Fig. 3.2H). It is subparallel to, but off strike from, the projection of DSGSD-1. Evidence of surface breaching (e.g., a physical scarp or a back-crack; see Henderson et al., 2011) is absent, indicating that if the trace is real, the responsible structure is under-developed. 


\section{Extension as a DSGSD to the northwest}

Tolgensbakk \& Sollid (1988) mapped a postglacial fault/ fissure (ff $f_{4}$ in Fig. 2; see Fig. 5C-E) directly to the northwest of, and along strike to, the NVDF. A sketch map in Mauring et al. (1997) depicted the NVDF as continuing under the boulders as a presumably vertical 'diffuse postglacial fault' that ultimately linked to the $\mathrm{ff}_{4}$ trace. However, we consider it unlikely that $\mathrm{ff}_{4}$ represents a direct continuation of the NVDF. Its fanning, relatively discontinuous fractures are of a very different physical character than the much more linear and continuous NVDF. Furthermore, the NVDF does not exit the northwest side of the northwesternmost boulder deposit. Nor is its trace visible within the narrow strip between two adjacent boulder deposits on images, and was not mapped by Tolgensbakk \& Sollid (1988). Lastly, we were unable to resolve a topographically coherent lineament across the south-westernmost boulder deposit itself in the DEMdraped images (Fig. 5A-B).

The inverse three-point solution (see above) coincides with the back-crack of a relatively small (ca. 2.5E + 06 cubic meters) unstable rock body near the summit of Nordmannviktinden (Fig. 5F). The projected plane does not crop out on the slope below, suggesting DSGSD may be likely. A series of surface features indicative of DSGSD propagation appear behind the Nordmannviktinden cirque and to the northwest of the unstable rock body. Mapped as postglacial fault/fissures by Tolgensbakk \& Sollid (1988) and striking at high angles to the trace of the projected plane, many are appropriately oriented for gravitational slumping towards the free face. Others strike subparallel to the projected plane, but are discontinuous and disappear within ca. $100 \mathrm{~m}$.

Our observations from both ends of the NVDF suggest the most optimistic length of continuous surface rupture can be no more than $6 \mathrm{~km}$ From data presented below we consider a more reasonable limit to be zero.

\section{Topographic displacement}

Because the NVDF is not resolvable on the $1 \mathrm{~m}$ vertical resolution, $25 \mathrm{~m}$ DEM we were unable to directly measure its along-strike variation in height. (The DEM constructed by Dehls et al. (2000), also of $1 \mathrm{~m}$ vertical resolution, is equally insufficient to extract details of the scarp's morphology). To obtain data indirectly we assumed that the scarp shadow width, measured perpendicular to the segment trace, would serve as a proxy for its height. We then estimated the heights of individual segments by developing a scarp shadow-height relationship.

We used the shadow cast by Peak 1335 to constrain the sun's azimuth and inclination on an aerial photograph (www.norgeibilder.no) that spanned the full length of the NVDF. We measured the width of the shadow cast by the feature in 50 places, plotted the shadow variation along strike, and applied a trigonometric correction to approximate its 'true' height (Fig. 11). Whilst small uncertainties in each of the input parameters lead inevitably to error in output, their effects will be constant along the trace of the NVDF. Although the 'true' height recovered at any one spot will be incorrect, the finalized trend line will simply shift up or down by the error value. Our results (Fig. 12) appear to have somewhat overestimated the scarp height, as is especially evident at its northwestern end. However, in general terms they fit well with the near-one-meter mean height estimated in the field by Bakken (1983), Dehls et al. (2000) and ourselves, as well as our field observation that the scarp height decreases consistently towards the northwest. The shadow proxy thus casts a meaningful constraint over the scarps along strike rate of decay.
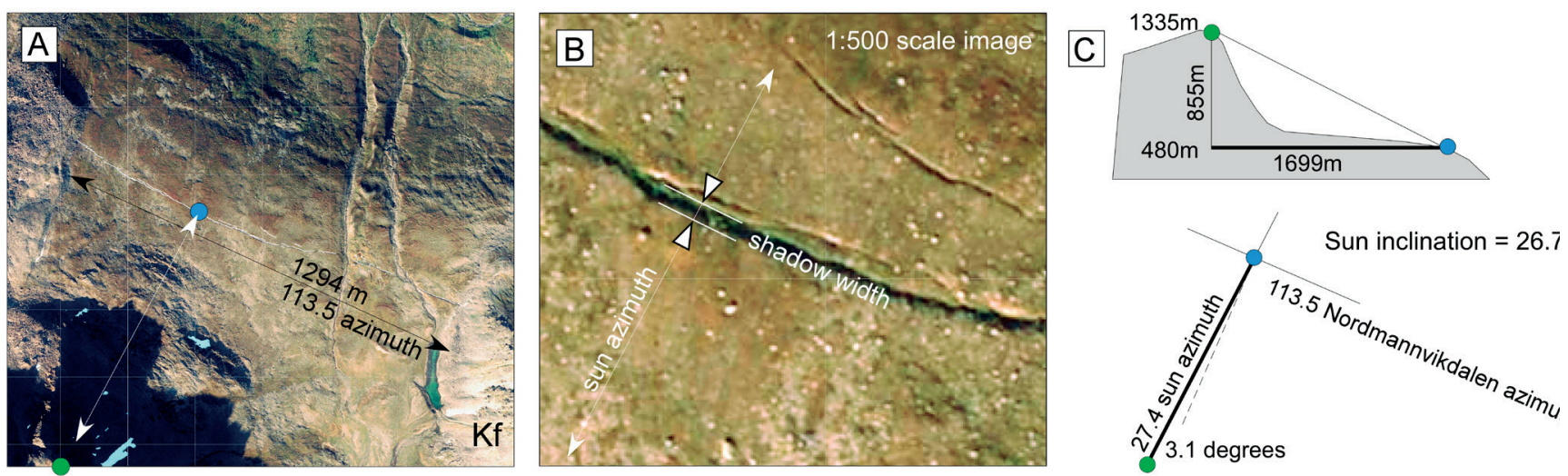

Figure 11. Maps and diagrams showing our method of measuring the scarp height of the Nordmannvikdalen feature (NVDF) with a shadow proxy. Subfigure (A): Small white dots indicate places where the width of the feature shadow was measured. (B) shows a close-up view of the scarp shadow. Shadow traces were digitized on-screen at a consistent 1:500 scale. (C) illustrates the geometric parameters of the simple shadow analysis used to determine an approximating shadow width to scarp height scaling relationship. The sun azimuth, obtained from the shadow cast by Peak 1335, is nearly perpendicular to the trace of the NVDF. Kf refers to Kistefjellet. Images modified from www.norgei3d.no. 

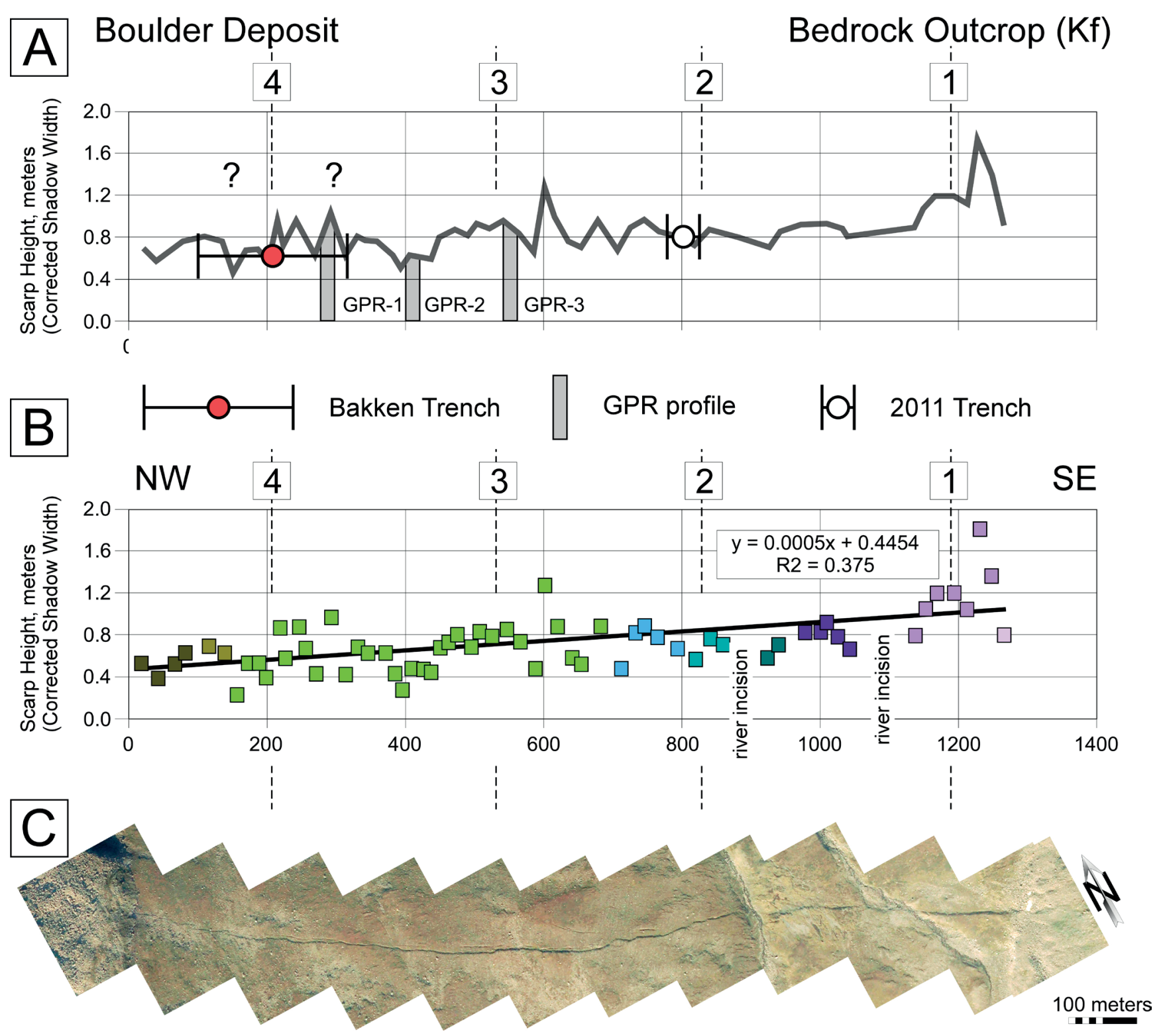

Figure 12. Graphs showing the Nordmannvikdalen fault/feature (NVDF) scarp height determined by correcting scarp shadow widths with the scaling relationship developed from shadow analysis. Shadows were measured at 1:500 scale in ArcGIS. (A) shows a line graph of corrected shadow width parallel to scarp. The abcissa begins at the northwestern end of the NVDF near the boulder deposit and ends at the bedrock outcrop. Topographic profiles of Fig. 3 are indicated by boxed numbers. (B) shows a weak but positive correlation coefficient characterizes the line fitting all of the corrected shadow width observations. Box colors indicate segments mappable as continuous features at 1:1000. GPR profiles relocated after Mauring et al. (1997). The Bakken trench was relocated using clues gleaned from Bakken (1983). Kf refers to Kistefjellet. Note that the actual scarp height near the Bakken trench is closer to $25 \mathrm{~cm}$. (C) shows an image stitch modified from www.norgei3d.no depicting the NVDF shadow in its entirety. Note the decay in shadow intensity from southeast to northwest.

\section{Magnitude scaling}

Empirical scaling relationships between $\mathrm{M}_{\mathrm{w}}$ moment magnitude, surface rupture length, and maximum displacement have been developed for reverse, strikeslip, and normal faults (e.g., Wells \& Coppersmith, 1994). For example, if the NVDF scarp was formed by footwall uplift following a single normal fault surface rupture, the following logarithmic scaling relationships should apply:

$$
\begin{gathered}
\mathrm{M}_{\mathrm{w}}=\mathrm{a}+\mathrm{b}^{\star} \log _{10}(\text { Maximum Displacement, } \mathrm{m}) \\
\mathrm{a}=6.61 \text { and } \mathrm{b}=0.7
\end{gathered}
$$

$\mathrm{M}_{\mathrm{w}}=\mathrm{a}+\mathrm{b}^{\star} \log _{10}($ Surface Rupture Length, $\mathrm{km})$ $\mathrm{a}=4.86$ and $\mathrm{b}=1.32$

We tested the NVDF against these equations using various length and height data. For a maximum displacement value of 1 meter the theoretical earthquake is ca. 
$M_{w}=6.6$ (Eq. 1). However, an event of this magnitude should have a surface rupture length on the order of 21 $\mathrm{km}$ (Eq. 2). A surface rupture of $6 \mathrm{~km}$ resolves to slightly less than $\mathrm{M}_{\mathrm{w}}=5.9$, in turn corresponding to a maximum scarp displacement of approximately $10 \mathrm{~cm}$ (Eq. 1). An alternative scaling provided by the University of Southern California's Open Seismic Hazard Analysis group (www.opensha.org/glossary-magScalingRelation) giving rupture length as equal to $10^{(-2.01+0.5+\mathrm{Mw})}$ provided values comparable to the equations of Wells \& Coppersmith (1994). Results for reverse and strike-slip faulting using the formulations of Wells \& Coppersmith (op. cit.) were also similar.

Whilst single earthquake Maximum Displacement to Rupture Length quotients (MD/RL) are generally less than 1/10000 (Wells \& Coppersmith, 1994), Maximum Displacement to Total Fault Length (MD/TFL) quotients for faults that have grown through many slip events are likely to be very different (Dawers et al., 1993; Kim \& Sanderson, 2005). Empirical displacement data compiled by Kim \& Sanderson (2005) indicate that a normal fault trace of ca. $1 \mathrm{~km}$ could present scarps between 1 and $10 \mathrm{~m}$ high. Given its geologic constraints the NVDF's $\mathrm{MD} / \mathrm{TFL}$ ranges between $1 / 1290$ and $1 / 6000$, permitting a possible history of many earthquakes.

Equations 1 and 2 suggest that erecting a $1 \mathrm{~m}$ scarp on a fault characterized by surface rupture lengths of ca. $1.3 \mathrm{~km}$ would require something on the order of 100 $M_{w}=5.0$ earthquakes. Surface ruptures of ca. $6 \mathrm{~km}$ (for which $\mathrm{M}_{\mathrm{w}}$ ca. 5.89 would be appropriate) would require some 10 events.

\section{Trenching observations}

In 2011 we opened (and closed) a ca. $1.5 \mathrm{~m}$ deep, $3 \mathrm{~m}$ long trench across, and orthogonal to, the NVDF. The trench was located at UTM Zone 34 (0485890, 7725723) in a sector where the scarp divides a shallower dipping upper plateau from a more steeply dipping lower slope (Figs. 2, 8). At this locality the NVDF scarp is approximately $1 \mathrm{~m}$ high and dips ca. $45^{\circ}$ towards the northeast. The sedimentologic characteristics of the NVDF were directly observed and described.

A diagram of results from a field trench was presented by Bakken (1983) as the last chapter of her MS thesis. Precisely where A.J.H. Bakken dug her trench is unclear. However, Bakken (op. cit.) illustrated her excavation site on a topographic cross-section. Her line drawing better matches the hill-slope of the northwestern end of the NVDF than that to the southeast (Fig. 10). The height of the scarp as shown on her trench log is on the order of $25 \mathrm{~cm}$, also indicative of a location nearer the boulder deposit. We therefore consider the Bakken trench observations to reflect the NVDF stratigraphy in the gen- eral vicinity of our topographic Profile 4 and GPR Profile 1 of Mauring et al. (1997).

\section{1 trench data}

Extending more than a meter to the upslope and downslope sides, our trench completely transected the NVDF scarp (Fig. 13A, B). The stratigraphic column consists of two units: organic topsoil above and rootpenetrated, cobble-rich, pebbly and sandy inorganic soil below. The organic topsoil layer changed thickness across the scarp, from approximately $50 \mathrm{~cm}$ above it to approximately $10 \mathrm{~cm}$ below. No break in the stratigraphy of the layered beds was observed (Fig. 13C, D). The contact between organic and inorganic soil was linear and largely surface-parallel. A colluvial wedge (e.g., material eroded from an upper fault scarp surface and transported to bury the scarp foot; see McCalpin, 2009) was not detected. The difference in elevation between the up- and down-scarp sides of the NVDF (e.g., the surface monocline) is entirely made up by the variation in thickness of the organic topsoil (Fig. 13C-E).

The topographic scarp and the increase/decrease in organic soil thickness coincide with the location of a well pronounced zone of oxidation. On the up-scarp side the oxidation layer lies below the surface at the contact between organic and inorganic soil. At the scarp it abruptly drops to about $70 \mathrm{~cm}$ below the organicinorganic transition. On the down-scarp side it rises to just below the surface, once again at the soil contact. The oxidation zone does not follow stratigraphic, sedimentologic, or textural layering (Fig. 13F). As well as to the change in topsoil thickness, the scarp maps to an upward step in the oxidation zone preserved in the soil horizon immediately below the surface.

\section{Bakken trench observations}

Our trench observations do not relate easily to the sketch log presented by Bakken (Fig. 14; Bakken, 1983). Bakken (op. cit.) described the NVDF as a crack in well consolidated glacial moraine deposits, at least $5 \mathrm{~m}$ thick. The crack was filled by less-compacted sand, gravel, and cobbles. A liberal translation of the description given by Bakken is as follows:

"To investigate the crack in Nordmannvik valley more closely [a trench] was dug in it. A field shovel was used, and it suited well both as a pick axe and a regular shovel. The first few meters were easy to dig, but further down, the material in the middle portion was transported up with a bucket. The side of the crack needed to be secured because the easily excavated material in the middle section had a tendency to collapse. The excavation was terminated at about $5 \mathrm{~m}$ depth, where it was very cramped, dark and dangerous in the hole. The crack and its infill seemed to 

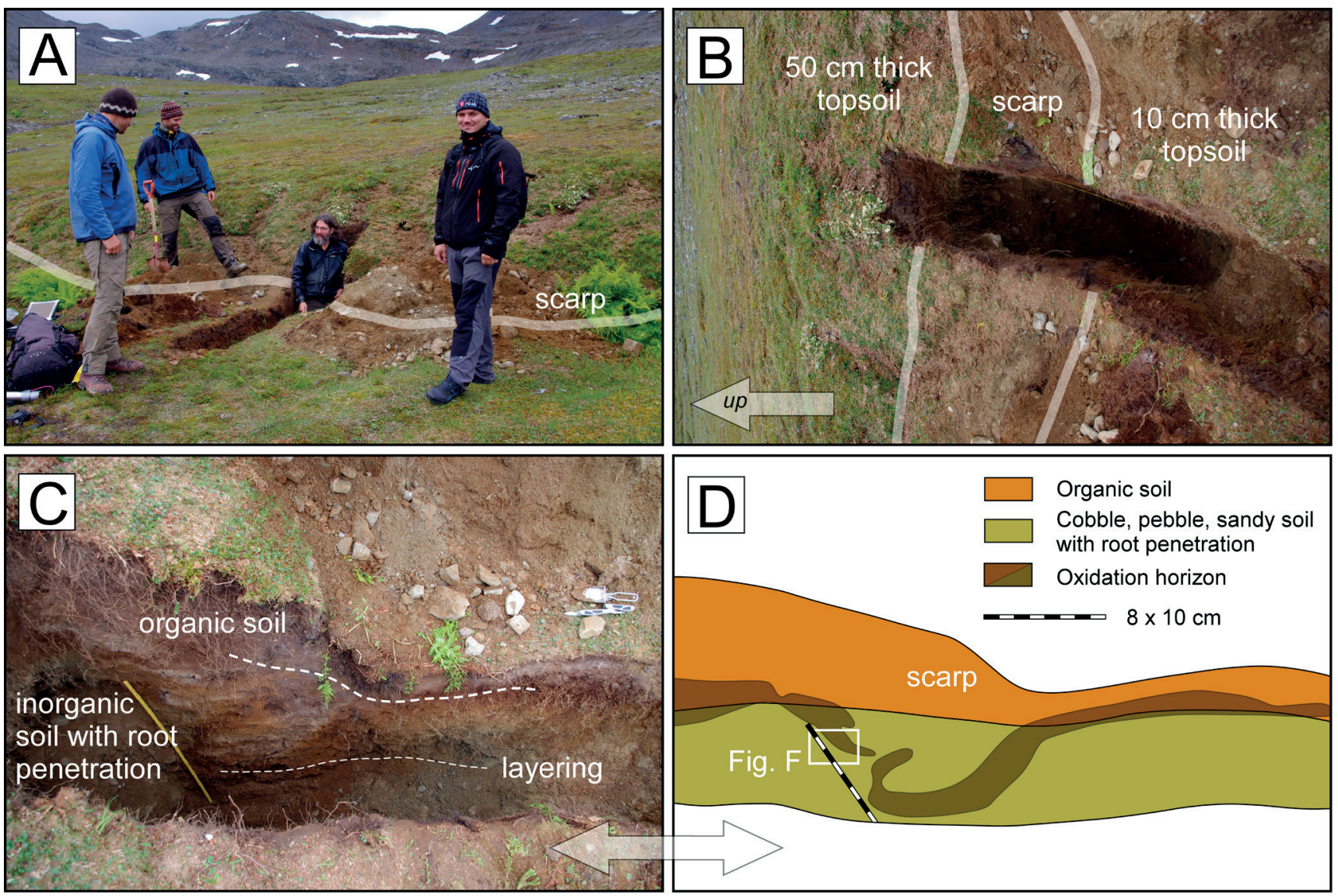

Organic soil

Cobble, pebble, sandy soil with root penetration
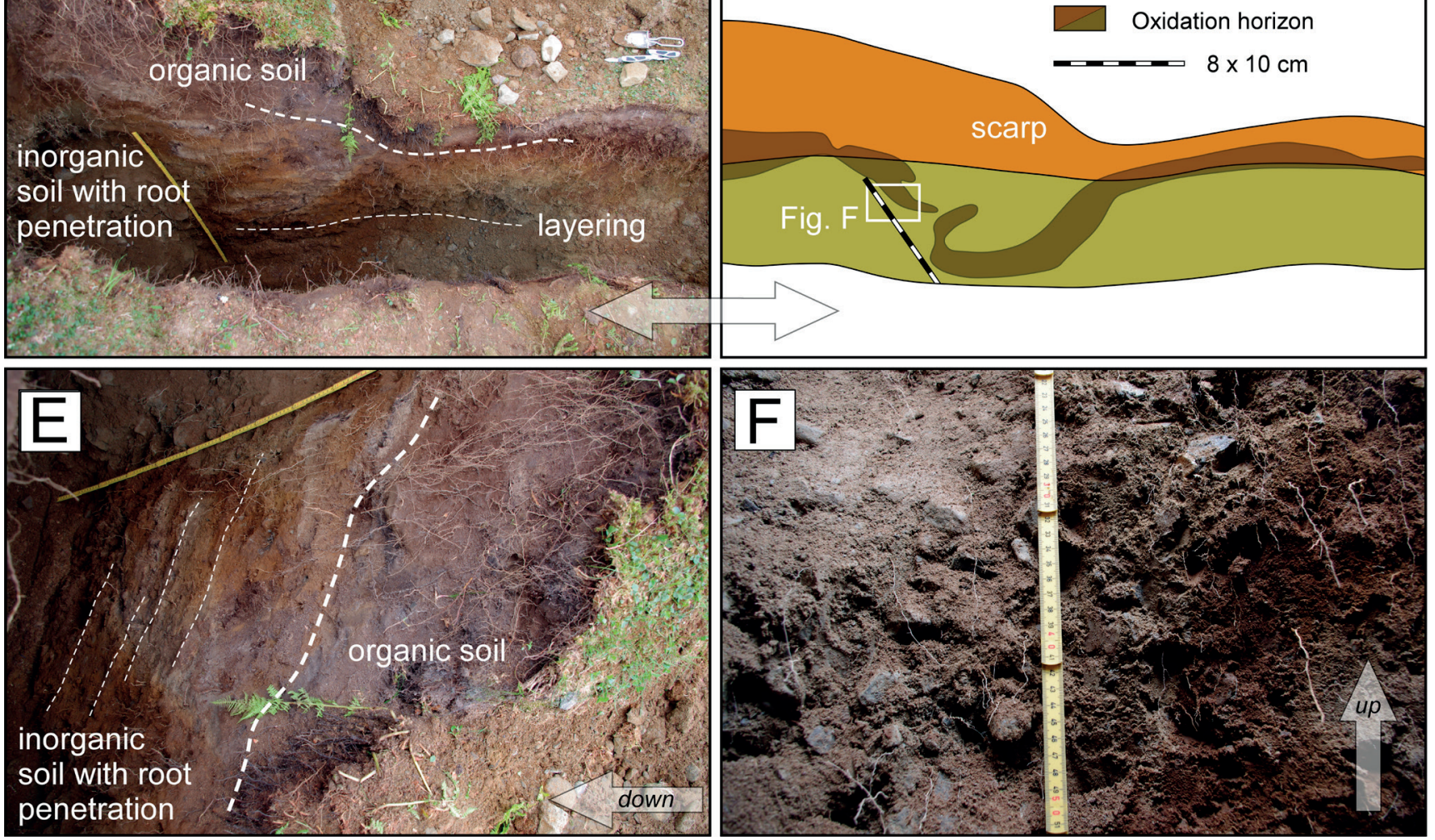

Figure 13. Documentation of the 2011 trench site. Subfigures (A, B) show an overview of the trench site looking to the south (A) and the southwest (B). Translucent white line represents the NVDF scarp. The trench extends completely across it. (C-E) show an overview of the northwestern trench wall, (D) Continuous, nearly horizontal layering is present within the inorganic soil. No fault plane and no colluvial wedge indicative of the eroded face of a footwall exposed by faulting were present. The upper organic soil layer changes from ca. $50 \mathrm{~cm}$ thickness above the scarp to ca. $10 \mathrm{~cm}$ below it. Note the linear, nearly horizontal contact between organic/inorganic soil units. Stratigraphic layering in the cobble/pebble inorganic unit below follows the contact. No offset or deformation is present. Visible part of the ruler is about $60 \mathrm{~cm}$ long in both $(C)$ and $(E)$. (F) shows the vertical drop of the oxidation zone below the surface step. Neither throw nor any change in sedimentological or textural nature across a structure was recorded, and the scarp itself is composed entirely of organic topsoil.

continue as a sheet at least a few meters deeper.

The aim of digging was to uncover the bedrock, which could not be reached. But there was at least shown to be an over $5 \mathrm{~m}$ thickness of tightly packed moraine deposits. The moraine material did not have structures that could show any displacement between the crack sides. The distance between the hard-packed sides varied, and decreased with the depth."

- translated from Bakken (1983) by the Authors. 

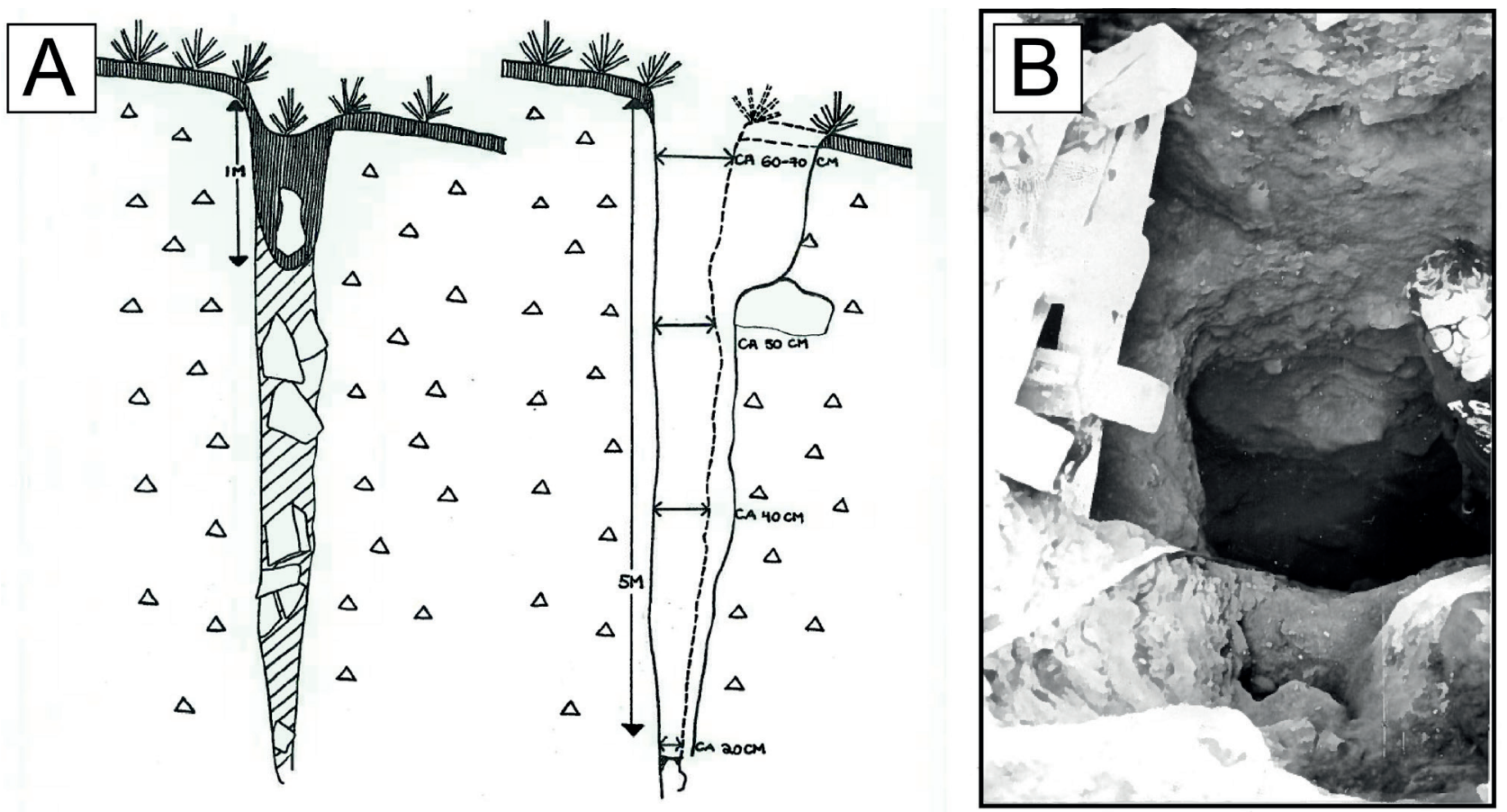

Less-consolidated sediments

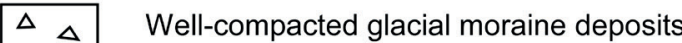

Soil deposits

Figure 14. Trench data from Bakken (1983). Subfigure (A) reproduces her cross-section interpreting the NVDF at this site as a formerly open fissure within well consolidated moraine deposits, subsequently filled by less compacted sediments and larger cobbles, and capped by a soil profile. Note the height of the scarp in this locality is on the order of $25 \mathrm{~cm}$, and its cross-section indicates it experienced sinkhole-like drainage when open. (B) shows the view into the trench during excavation (op. cit.). Vertical wall above field assistant is the footwall (e.g., scarp side). Material just below the support timbers is poorly consolidated infill.

\section{Ground Penetrating Radar (GPR)}

The GPR study executed by Mauring et al. (1997) comprised three profiles (Fig. 15A-C, top panels). Similar descriptions of GPR Profiles 1 and 2 were given by Mauring et al. (1997, 1998). Dehls et al. (2000) concluded that a) up-dip extrapolations of strong reflectors in GPR Profiles 1 and 2 intersect the NVDF scarp; b) one GPR Profile 1 reflector could possibly represent a fault with Holocene activity; and c) the three reflectors resolved a continuous fault plane extending at least the length of the three GPR profiles.

The reports were archived sufficiently well that peaks and troughs of the individual radargrams (traces) could be accurately and precisely identified. Because the data were migrated and the GPR profiles were orientated at a high angle to the NVDF and reproduced at 1:1 scale, the geometries of individual features can be presumed to be true. (The stacking velocity used for depth conversion affects the geometry; if overly high, so too will be reflector dips. Mauring et al. (1997) elected $0.11 \mathrm{~m} / \mathrm{ns}$ ). Curiosity piqued, we prepared line drawing interpretations for each GPR profile.

\section{The data}

The GPR method employed by Mauring et al. (1997) samples reflections emanating from boundaries with different electrical permittivities. Although the physical resistivity of the rock is an important parameter, permittivity can also be affected by water content and composition. These in turn are affected by porosity and permeability of the medium. In shorter words, reflectors can, but do not necessarily, image compositional layering such as the soil/bedrock interface.

Permittivity being strongly dependent upon the presence or absence of water, one GPR reflector cannot truly be said to be cross-cut by another. However, under the assumption that groundwater follows fractures or is electrically more significant in permeable layers, high-angle junctions between reflectors are likely to mark changes in orientation of the rock or soil fabric. We thus defined five Information Packages (IPs) and dated them using the laws of cross-cutting relationships (Steno, 1669) and superposition (op. cit.).

The distributions of the subsurface reflector families appear generally consistent between the three GPR pro- 
files. A set of reflectors parallel to the topographic surface show excellent radargram continuity within the first one or two meters. Between ca. 5 and $10 \mathrm{~m}$ depth the individual reflectors are shorter (ca. 10-20 radargrams) and sinuous to wavy in shape. However, they remain almost entirely parallel or subparallel to the topographic surface, are densely spaced, and strongly expressed. With one exception in GPR Profile 3, more steeply dipping reflectors are absent until ca. $>10 \mathrm{~m}$ depth. Below ca. 10 meters, many reflectors with migrated dips between $48^{\circ}$ and $50^{\circ}$ to the northeast (Mauring et al., 1997) become prominent. In places, short, wavy reflectors give the impression of open folds. Longer (greater than ca. 20 radargram) reflectors parallel or subparallel to the topographic surface and deeper than ca. 5-10 m are not evident on GPR Profile 1, present in places on GPR Profile 2 (Fig. 15B), and more common on GPR Profile 3 (Fig. 15C).

\section{The drawings}

For purposes of visualization IP-1 was divided into two subunits that respectively connected the early arrival peaks (black-filled) and troughs (unfilled). Although the deeper returns are more convoluted, IP-1 can be mapped as a continuous and unbroken feature along the entirety of each GPR profile. As corrected by Mauring et al. (1997), the reflectors of this group, all essentially surfaceparallel, together comprise about $5 \mathrm{~m}$ of thickness.

Coherent reflectors were difficult to map immediately below the deepest IP-1 horizon. Below a nebulous transition zone we identified a series of sharply defined, discontinuous, wavy reflectors running parallel or at shallow angles to the topographic surface (IP-2). In each GPR profile at least one continuous IP-2 reflector was interpreted to cross-cut the subsurface projection of the NVDF scarp. The individual reflectors within this unit tend to become shorter and less distinct with depth. Our division between IP-2 reflectors and shallow-dipping reflectors of the lower units was therefore somewhat subjective. Our most useful criterion was the overwhelming absence of steeply-dipping reflectors within IP-2.

IP-3 to IP-5 reflectors are deeper, and of varying lengths and dips. In some cases cross-cutting relationships can be deciphered. For example, the inclined reflectors interpreted by Mauring et al. $(1997,1998)$, and Dehls et al. (2000) as aligning with a downwards projection of the NVDF scarp (marked by a red arrow in Fig. 15B) appear to be 'truncating' the more subhorizontal reflectors. We defined these and similarly inclined reflectors as IP-3, and consider them as the youngest of the deepest three units. In cases where cutting relationships were ambiguous, we classified the reflectors as IP-4. An example is marked by a green arrow in Fig. 15B. An apparent antiform-synform morphology resolved in a few places by reflectors of IP-5 (shown as dashed lines in GPR Profile
2) may be either a processing artifact (e.g., the ghost of a hyperbola) or a true indication of internal structure, such as the open to tight folding observed in nearby bedrock outcrops in stream gullies and on Kistefjellet.

\section{What lies below?}

On all three GPR profiles the continuous IP-1 surface reflectors are draped in a half fold across the NVDF. A very generous eye can resolve a wraith-like monocline within the uppermost IP-2 stratigraphic unit (Fig. 15A radargram inset). Even this becomes lost within the main body of IP- 2 reflectors. Accepting the depth scale as true indicates that the IP-1 monocline persists to ca. 3-5 $\mathrm{m}$. Because the stratigraphic horizons we observed in our trench are essentially horizontal we cannot relate the IP-1 monocline to geological structures such as the organic-inorganic soil contact or the continuous, near-horizontal layering in the sandy soil below it. We hypothesize that the IP-1 monocline is largely a geophysical manifestation of the surface topography, e.g., the scarp.

Mauring et al. (1997) interpreted a series of weak reflectors oriented subparallel to the topographic surface at about 5 to $10 \mathrm{~m}$ depth as a possible bedrock interface. Mauring et al. $(1997,1998)$ also described a series of gently-dipping reflectors on GPR Profile 2 (bracketed by dark gray arrows in Fig. 15B) as cross-cutting more steeply dipping reflectors, and suggested they may have marked the groundwater level at the time of measurement. However, when constructing our line drawing we were not able to satisfactorily resolve a consistent transprofile cross-cutting relationship for the weak reflectors. Moreover, whilst a similar reflector set does not appear on GPR Profile 1, several are present at different depths in GPR Profile 3 (bracketed by dark gray arrows in Fig. 15C). Lastly, a noticeable contrast exists between the dominantly surface-parallel structural grain of IP-2, where steeply-dipping IP-3 and IP-4 reflectors are absent, and the apparent truncation of these last units near the base of IP-2. (Whilst cognizant of artifacts, we note also a contrast between the more surface-parallel IP-2 reflectors and the apparent antiform-synform morphology resolved in a few places by IP-5, most prominently in GPR Profile 2). These disparities seem to us as inconsistent with a water table source for the weak reflectors. We suggest that the NVDF sediment-to-basement interface lies at the gently dipping horizon marked by dark gray arrows on GPR Profile 2 in particular and at the base of the IP-2 unit in general. The coherency of the IP-2 reflectors may indicate the presence of a relatively consolidated sedimentary sequence such as the fractured moraine deposit reported by Bakken (1983). 
$15 \mathrm{~A}$
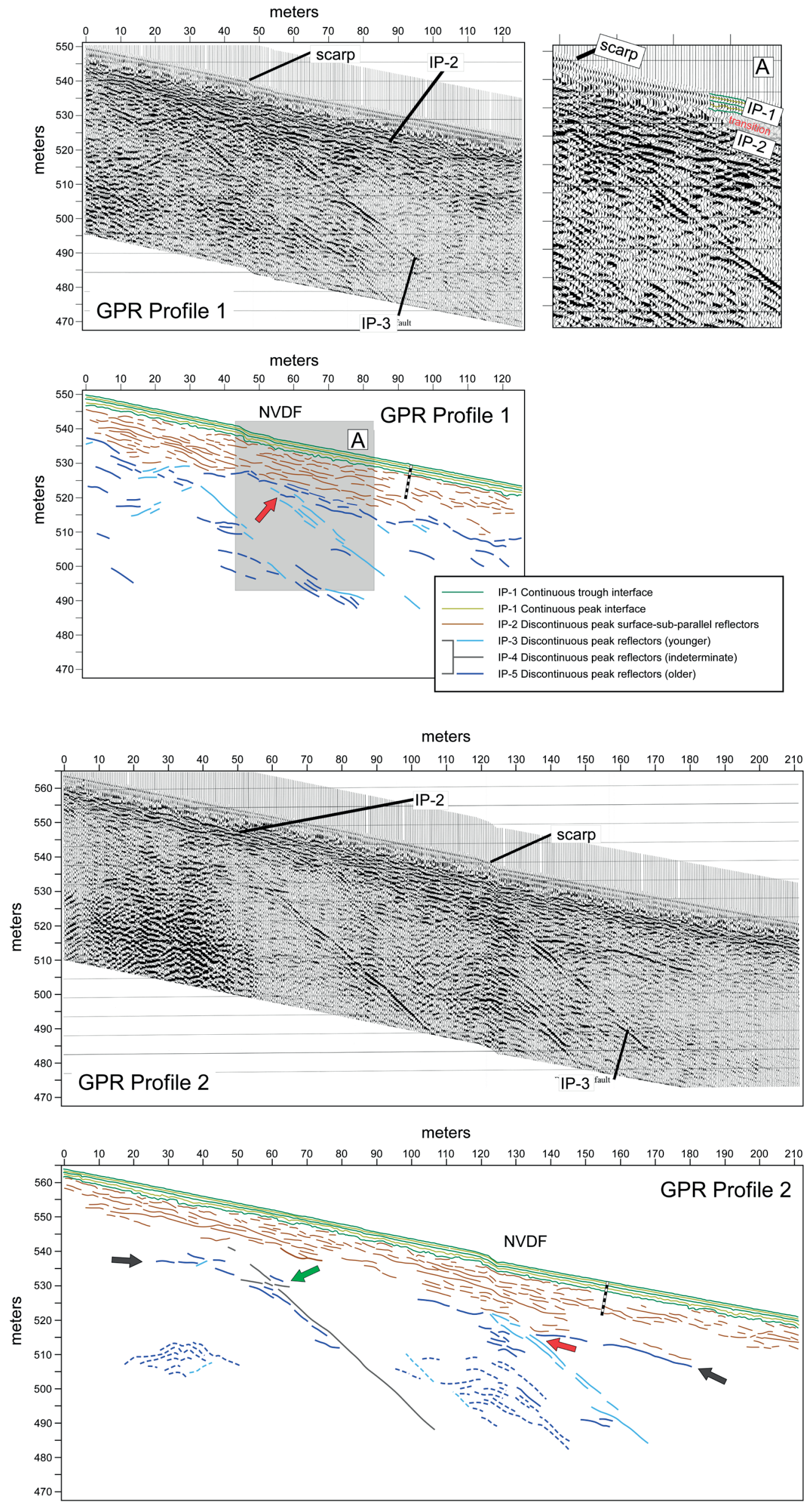
$15 \mathrm{C}$
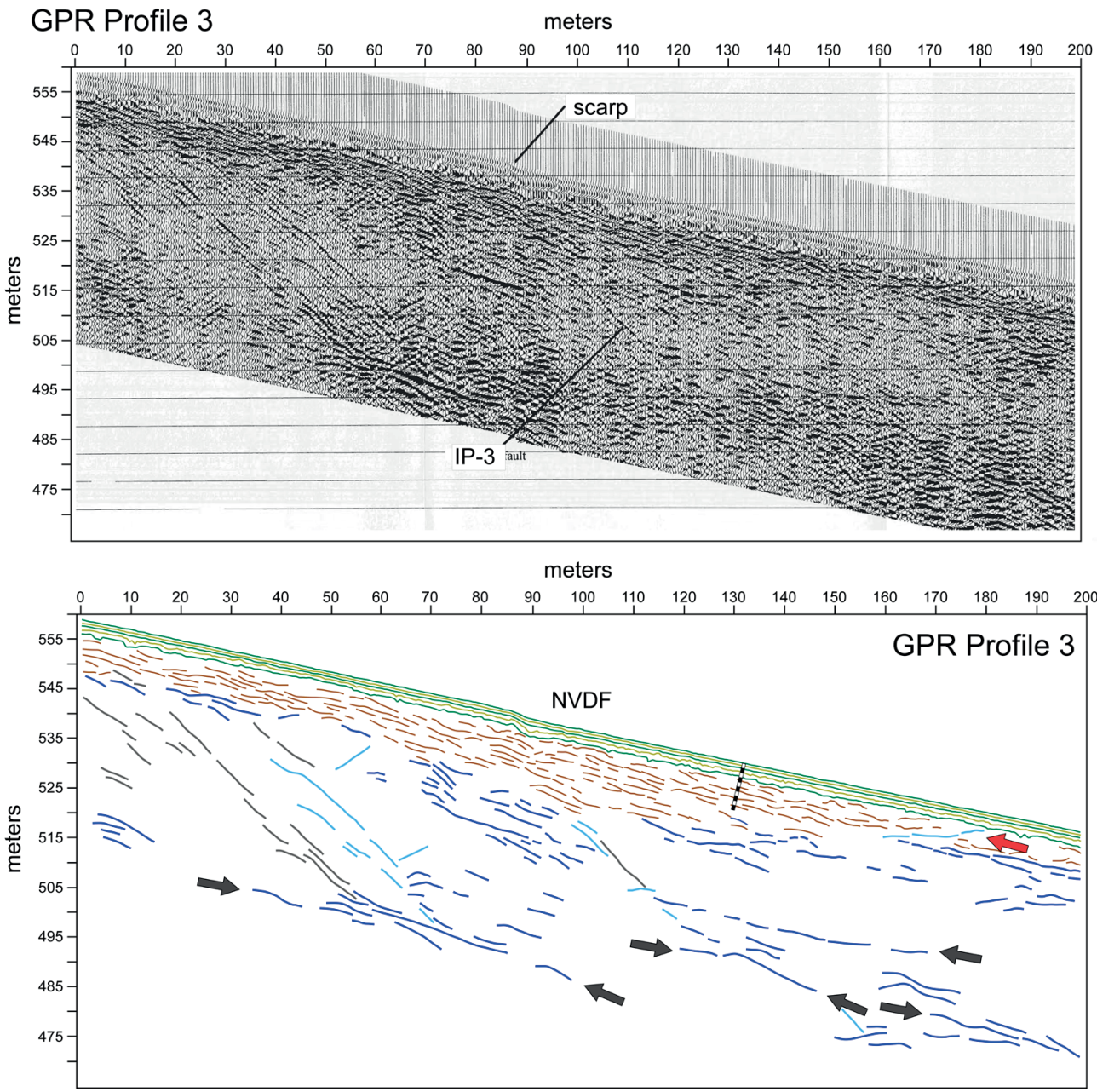

Figure 15. (A) Ground Penetrating Radar (GPR) Profile 1 from Mauring et al. (1998). Top: Original presentation from Mauring et al. (1998). Bottom: Line drawing interpretation of GPR Profile 1 following conventions described in the main text. Note full continuity of IP-1 and partial continuity of IP-2 across the Nordmannvikdalen feature (NVDF). Red arrow indicates cross-cutting relationships discussed in the main text. Inclined scale bar represents $10 \mathrm{~m}$. Inset A (upper right) shows details of transition zone between IP-1 and IP-2, and the termination of IP-3 at the IP-2 level. (B) Ground Penetrating Radar (GPR) Profile 2 from Mauring et al. (1998). Top: Original presentation from Mauring et al. (1998). Bottom: Line drawing interpretation of GPR Profile 2 following conventions described in the main text. Note full continuity of IP-1 and partial continuity of IP-2 across the Nordmannvikdalen feature (NVDF). Green, red, and dark gray arrows, respectively, mark the indeterminate crosscutting relationship, the series of prominent slope-parallel reflectors, and the 'step' described in the main text. Inclined scale bar represents $10 \mathrm{~m}$. Key to GPR reflector Information Packages same as in Fig. 15A. (C) Ground Penetrating Radar (GPR) Profile 3 from Mauring et al. (1997). Top: Original presentation from Mauring et al. (1997). Bottom: Line drawing interpretation of GPR Profile 3 following conventions described in the main text. Note full continuity of IP-1 and partial continuity of IP-2 across the Nordmannvikdalen feature (NVDF). Red and dark gray arrows indicate the unusual IP-3 reflector and the prominent IP-5 slope-parallel reflectors discussed in the main text. Inclined scale bar represents $10 \mathrm{~m}$. Key to IP reflector Information Packages same as in Fig. 15A 


\section{Discussion}

There is nothing either good or bad, but thinking makes it so. Following birth as a $5 \mathrm{~m}$ hole in the ground excavated by Bakken at some time during the early 1980s, the NVDF became a postglacial fault/fissure line on the map of Tolgensbakk \& Sollid (1988). It then made a leap into the geologic literature as a fully fledged neotectonic fault (Dehls et al., 2000; Stewart et al., 2000). It has subsequently been cited as evidence for postglacial normal faulting by more than a few authors (e.g., Bungum et al., 2010; Olesen et al., 2013; Sutinen et al., 2014), including ourselves (Bunkholt et al., 2013). Yet an honest tale speeds best, being plainly told. Is it a fault scarp? Or isn't it?

\section{Theoretical issues}

Normal faults (and in Kåfjord, many gravitationally failing rock hillsides; see Henderson et al., 2011) exhibit a distinctive and diagnostic morphology (e.g., Dawers et al., 1993; Destro, 1995; Burbank \& Anderson, 2001; Densmore et al., 2004). They have no scarp at the tip (the point past which surface rupture has not propagated) and rise to a maximum scarp height near the midpoint of the ruptured segment. The scarp height must then decrease in concert with the segment strike until the termination of surface rupture at the distal tip. If multiple fault segments have linked, the throw can become a summation of that across the individual faults prior to linkage (see conceptual examples in Burbank \& Anderson, 2001).

Whilst many of the individual 'sawteeth' of Fig. 12A might reflect inaccurate shadow measurements, the overall long-wavelength increase in the scarp height proxy is internally consistent. The XY plot (Fig. 12B) shows a weak, albeit reasonable correlation coefficient describing a line that climbs gently from northwest to southeast. The rise matches our field observations, and could be interpreted to reflect a single degraded scarp or a series of linked scarps with a consistent decay towards the boulder deposit to the northwest.

The along-strike coexistence of dextral and sinistral en échelon linkage patterns (Fig. 6) suggests it is unlikely that the NVDF is the product of a lateral fault. The only apparent GPR offset (Fig. 15B, red arrow) would prescribe a significant component of normal slip. However, if its scarp height is considered the product of a single tensional earthquake, the NVDF fails the generalized, well-accepted magnitude/length scaling relationships of Wells \& Coppersmith (1994) by close to one (or, given a more realistic maximum surface rupture length, nearly two) order(s) of magnitude. Reverse and strike-slip styles of faulting fit the appropriate empirical length-to-displacement relationships equally poorly.

Fully aware of the problem, Bungum et al. (2010) suggested that the NVDF might be considerably longer than 2 $\mathrm{km}$. However, the data presented above show this is not so. It is possible to argue that the postglacial fault/fissure system delimiting the inner margin of Kistefjellet's DSGSD-1 is part of an NVDF surface rupture, but because it cannot be extended beyond (or even into) the off-strike structures of the SE flank (Fig. $3 \mathrm{H}$ ) the length so gained is not very helpful. Similarly, whilst Nordmannviktinden's DSGSD-2 might be part of the NVDF structural architecture, its demise beneath overburden places a second fixed limit on earthquake surface rupture length. Should the NVDF dip more steeply to the northwest, we would expect its trace to be exposed in the narrow strip between the overlying boulder deposits - but it is not. There is too little wiggle room in the house to satisfy desire.

\section{Fault-based scenarios}

A fault is a fault; whether by tectonic forces or rapid deglaciation we demand only that one side can be shown to have moved a measureable distance relative to the other. Were the NVDF soil scarp formed during a normal fault throw, four possibilities can be tested by existing data. The tests apply also in principle to reverse and oblique offsets.

Partial or total surface rupture. Although Bakken (1983) explicitly stated that no offset strata existed within what she termed well-compacted glacial moraine deposits, such sediments are commonly massive. Visible sedimentary structures would probably be an exception as opposed to the rule. Furthermore, her sketch hints at an apparent normal-sense component of throw of about 20 $\mathrm{cm}$ at the base of the soil horizon. Thus, the fissure itself could be interpreted as evidence for a localized normal fault rupture that was subsequently covered by organic soil.

Despite the differences in descriptions, our excavation can be generally compared to the uppermost meter of Bakken's. We did not make contact with the moraine material reported by Bakken (1983), and thus we cannot claim it is not present below our deepest level. Our interpretation of the GPR data implies that had we dug deeper, we would likely have encountered more consolidated material. It is possible, too, that we might then have also discovered a fissure. However, in the absence of yet another trenching exercise this hypothesis is untestable.

Evidence against a true surface rupture is nevertheless overwhelming. Offset stratigraphic horizons and depositional wedges related to scarp collapse and/or erosion are the most characteristic features visible in trenches crossing surface faults (McCalpin, 2009 and references therein). Our excavation across the NVDF revealed neither, and none were reported by Bakken (1983). The inorganic soil layering in our trench was both surfaceparallel and unbroken, as too is the IP-1 reflector stratigraphy. With one exception, the IP-3 reflectors that 
might be interpreted as fault planes cannot be traced into the IP-2 unit. Marked by the red arrow in Fig. 15C, the exception is of opposite dip and neither penetrates the IP-1 unit nor projects up to the NVDF scarp. The parts of the NVDF excavated by ourselves and imaged by Mauring et al. $(1997,1998)$ encompass close to one half of the NVDF's surface length. Using the magnitude scaling and normal fault growth models as guides, it is difficult to conclude that a surface rupture producing a scarp height of ca. 10-20 cM (e.g., $5.9<\mathrm{M}_{\mathrm{w}}<6.1$ ) could have been confined only to the area near the Bakken trench.

'Blind' rupture. A recent normal fault footwall heave could have displaced the soil overburden without carving through it. The amplitude of the surface monocline thus formed would mimic the subsurface scarp at any point along its line of rupture.

The fault monocline interpretation hangs on the assumption that one particular subset of IP-3 reflectors is a set of reactivated fault planes as opposed to simply bedrock fractures or foliation planes. This assumption is not ironclad. Bearing in mind the potential for artifacts, we interpreted the wavy reflectors of IP-5 to represent folded biotite schist fabrics such as the transposed bedding and/or foliation planes known from the perennial streambeds (see Dehls et al., 2000) and on Kistefjellet (Fig. 3.1B; Zwaan et al., 2006). These planes are cross-cut by higher-angle fractures; we interpreted IP-3 reflectors in such terms. IP-4 reflectors can be representative either of higher-dipping transposed bedding/foliation or fractures.

Mauring et al. (1997) suggested one prominent, truncated IP-5 reflector on GPR Profile 2 (marked by a red arrow in Fig. 15B) could be imaging a hydraulic head drawdown related to elevated porosity within a fault zone. Under our GPR model it might be interpreted in terms of a ca. 1-2 $m$ down-to-the-NE step in the bedrock surface. A nontectonic explanation is perfectly plausible: Norwegian mountain slopes are replete with bedrock benches shaped by glacial plucking, frost wedging, and other erosional processes. Such benches could appear in cross-section exactly as seen in GPR Profile 2 . We favor this interpretation over the water table or fault offset hypotheses on the grounds that the base of the IP-2 unit does not appear similarly displaced in GPR Profiles 1 or 3 .

Although the topographic surface at our trench site is monoclinally deformed by about $1 \mathrm{~m}$, mirrored by the variation in topsoil thickness, the inorganic soil stratigraphic layering is not. Because the contact between the organic and inorganic soil units in our trench (Fig. 13C, D) almost certainly lies within the IP-1 layer, our contention is that IP-1 reflectors should not be interpreted as geologic layers within the upper sedimentary sequence. If we are wrong and the reflectors in the IP- 1 monocline actually do represent stratigraphic horizons that have been structurally warped, the deformation cannot extend laterally to our trench.
Lastly, if taken at face value the linear regression of Fig. $12 \mathrm{~B}$ implies that at a point a little greater than $2 \mathrm{~km}$ northeast of Kistefjellet the NVDF surface rupture decays to an amplitude of zero. Were we to correct in some way for the overestimation of scarp height by our shadow proxy, the zero point would be even less distal. The fault monocline hypothesis also cannot satisfy the magnitude scaling equations.

Pre-stratigraphic rupture. One remaining possibility is that the NVDF ruptured during or immediately after deglaciation, prior to the development of any significant soil or till/moraine cover. In this case, the presentday expression of the NVDF scarp must have formed by another process, such as gravitational soil creep across an existing exposed bedrock fault plane or DSGSD back-scarp. However, the absence of a monocline or step within either the stratigraphy in our trench or the IP-2 reflectors is problematic. To explain matters by rebranding IP-2 as bedrock does not help because IP-3 reflectors cannot be shown to unequivocally cross-cut the IP-2 unit beneath the NVDF (Fig. 15A-C; see especially Fig. 15 inset [a]), raising the question of why they are terminated within the bedrock unit itself. Deformation at a scale below the resolution of the GPR experiment is possible but completely untestable. As with the partial and blind rupture hypotheses above, the problem of rupture length and scarp height magnitude scaling would also remain outstanding.

Multiple ruptures. Wide variation exists within MD/ TFL quotients (Dawers et al., 1993; Kim \& Sanderson, 2005). A multiplicity of earthquakes for the NVDF is permissible and could be invoked to bypass the singleevent magnitude scaling problem. However, whilst lesser earthquakes are quite common in Norway, the absence of erosional wedges and the scarp's excellent preservation in a postglacial alpine setting renders implausible the hypothesis that many normal fault ruptures produced it.

\section{The NVDF enigma}

The evidence presented above indicates to us that the NVDF is almost certainly not a neotectonic fault formed by one or more Holocene earthquakes. We admit we are not entirely pleased by this conclusion. Given the many complementary lines of evidence pointing strongly towards the role of normal fault reactivation and growth in the Tertiary uplift of western Scandinavia (e.g., Redfield et al., 2005, Osmundsen et al., 2009, 2010; Redfield \& Osmundsen, 2009, 2013; Hendriks et al., 2010; Osmundsen \& Redfield, 2011; Johannessen et al., 2013; Ksienzyk et al., 2014), offshore Plio-Pleistocene sediment thicknesses that suggest a significant component of uplift probably occurred fairly recently (e.g., Rise et al., 2005), and shallow seismic data hinting that some nearshore normal faults were active during the Quaternary (e.g., Bøe et al., 1992) - not to mention Norway's pres- 
ent-day seismicity (e.g., Ahjos \& Uski, 1992; Bungum et al., 2005; Redfield \& Osmundsen, 2015) - it is a bit problematic to be removing neotectonic faults from the national map instead of adding them. Yet honest words best pierce the ear of grief. Although not entirely certain what the NVDF might actually turn out to be once all is said and done, we discuss some alternative possibilities below.

Glacial cracking? Deglaciation returns underlying strata from a more complicated state of stress to one where the third principal direction is essentially normal to the Earth's surface. Although the impact upon fracturing in the uppermost levels depends on a variety of conditions, it is generally accepted that rapid deglaciation can drive seismicity (e.g., Arvidsson, 1996; Wu \& Hasagawa, 1996). This hypothesis is commonly applied to Fennoscandia, either in full (e.g., Gudmundsson, 1999) or in part (e.g., Muir Wood, 2000; Bungum et al., 2010; Keiding et al., 2015; Redfield \& Osmundsen, 2015). The downward tapering fissure could plausibly have opened during or immediately after deglaciation. Bakken (1983) hypothesized as follows:

"The conclusion is that there must have been a cracking or fissuring in the moraine and possibly also in the bedrock. The mechanism that triggered it could have been rapid melting with an associated release of pressure, or other reactions in connection with a large local glaciation."

- translated from Bakken (1983) by the authors.

However, we have disposed of the possibility that the NVDF was formed instantaneously during a single earthquake. Albeit conceptually possible, the question of whether or not a tension crack in a compacted morainelike lithology can open over a relatively lengthy period of time as a response to a stress drop following glacial melting is outside the remit of our paper.

Deep-seated Gravitational Slope Deformation (DSGSD)? An almost unbelievable concentration of DSGSDs afflicts Kåfjord (e.g., Jarman, 2009; Osmundsen et al., 2009; Bunkholt et al., 2011, 2013). More than a few areally significant boulder deposits litter the northfacing lower slopes of Nordmannvikdalen (Tolgensbakk \& Sollid, 1988), and many were probably emplaced by rock avalanches (Jarman, 2009). Bakken (1983) reported cracks at the summit of Nordmannviktinden, which were subsequently mapped by Tolgensbakk \& Sollid (1988). These cracks partly delimit DSGSD-2 (Figs. 2, 5F). As described above, both its back-crack and the probable innermost controlling structure to DSGSD-1 on Kistefjellet can be projected into the NVDF with a plane that dips commensurately with the reflectors of IP-3.

Mauring et al. (1997, 1998) raised the spectre of gravitational slumping as a possible mechanism. Without the advantage of today's stunning aerial images, Dehls et al. (2000) argued against it. These new datasets indicate DSGSD deformation that is consistent with IP-3 spatial orientation and lies adjacent to both ends of the NVDF could be a significant factor. Were the NVDF scarp merely the propagating extension of one or both DSGSDs, the issue of magnitude scaling would become completely irrelevant and thus neatly explained.

DSGSD deformation could also provide a plausible explanation for the origin of the fissure reported by Bakken (1983). However, several problems with the hypothesis exist. Dehls et al. (2000) correctly noted the lack of lateral accommodation (translation) structures at either end of the NVDF. This can be argued away on its southeastern end by invoking hard or soft linkage between the Kistefjellet DSGSD-1 and NW-dipping rock fabrics of the NVDF such as those imaged by IP-3 and IP-4. Because the scarp decays to the northwest (Fig. 12) it is reasonable to suppose that so too does the subsurface deformation, disposing of the need for the missing transfer at or under the boulder deposits.

The $10^{\circ}-12^{\circ}$ true dip of the hillside below the NVDF is quite gentle and the ca. $48^{\circ}$ and $50^{\circ}$ dips of the IP-3 reflectors do not daylight (i.e., penetrate the surface) (Fig. 16). Development of a complex failure plane linking many discrete and particularly low-angle structures would be required. The NE-dipping foliation and bedding planes pictured in fig. 10 of Dehls et al. (2000) offer a ray of hope in this direction, as too do the $10^{\circ}$ NE-dipping foliation measurement and the very lowangle, presumably extensional, 'backsliding thrust' of Zwaan et al. (2006; Fig. 3.1D). DSGSD failures utilizing compound structures are common elsewhere, and also known locally: to the south of Nordmannvikdalen, Bunkholt et al. (2011), Henderson et al. (2011) and Böhme et al. (in press) have described large-volume unstable rock compartments with relatively shallow $\left(20^{\circ}-30^{\circ}\right)$, probably compound, basal sliding planes.

However, uncertainties remain. One problem is that the bulge typical of DSGSDs is not apparent at the foot of the slope (Dehls et al., 2000). Another is the map pattern of its scarp. As noted by Dehls et al. (2000), its trace is unlike the more arcuate shape that characterizes most DSGSDs. So too are its convex-downslope lobe-like segments (Fig. 7). Furthermore, the GPR data do not show consistent offset of the presumed bedrock surface. A fourth problem is presented by the undisrupted inorganic soil stratigraphy near the point where the scarp achieved its greatest magnitude.

This last feature offers a clue. Recalling that in the vicinity of our trench the scarp itself was composed entirely by topsoil, we exit the rock column in search of a surface solution. 

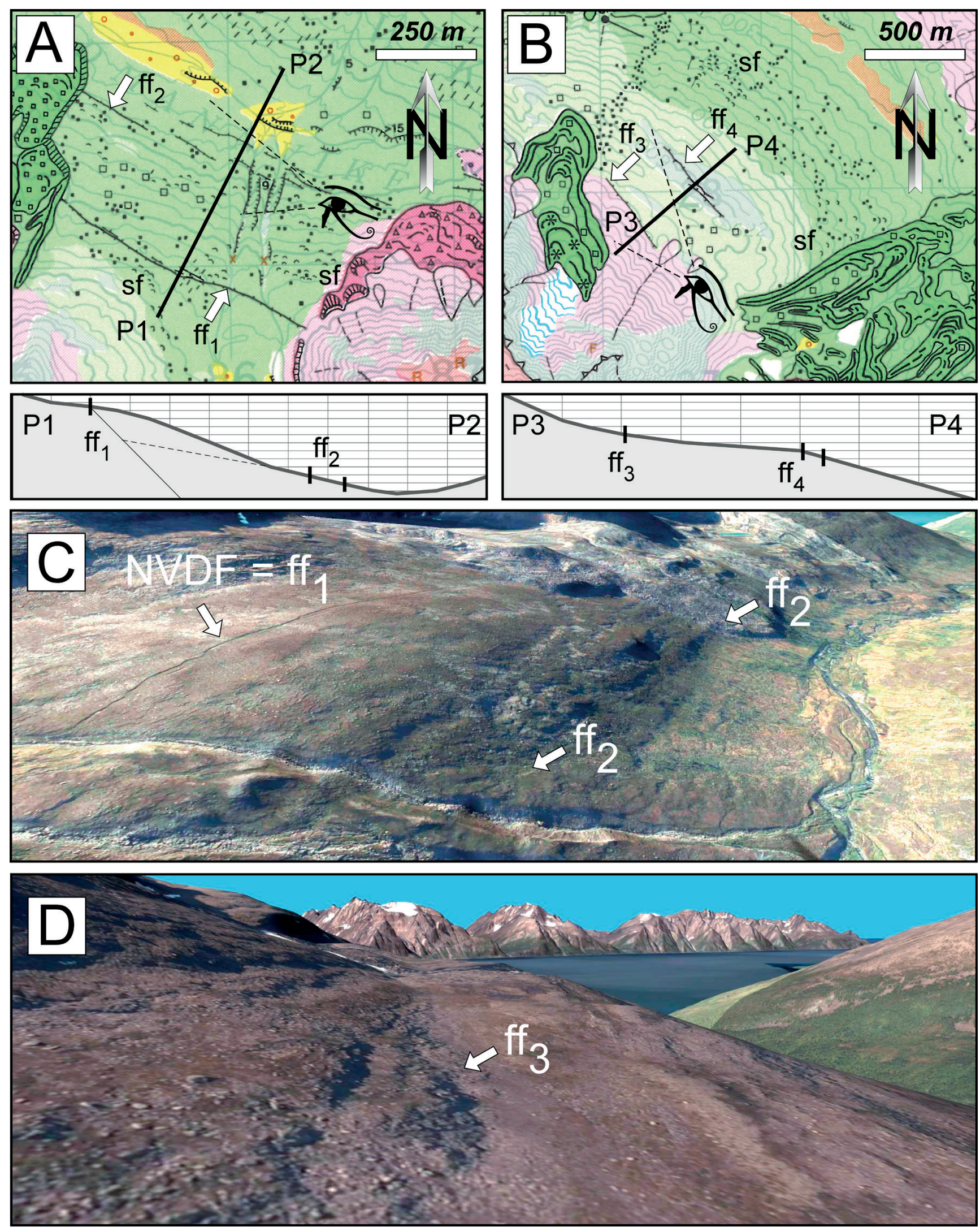

Figure 16. Subfigures (A) and (B) (see Fig. 2) show the NVDF (ff1) and additional postglacial faults/fissures (ff2-4) mapped by Tolgensbakk \& Sollid (1988) downslope of the NVDF and to the northwest of it. Solifluction lobes (sf) were mapped on both lower slopes. Note that both the upper and the lower ff features are roughly hillslope parallel. Topographic cross sections P1-P2 and P3-P4 below both panels show true dip. Note how these (ff) features (vertical black bars) are located adjacent to significant hillside changes in slope. Dipping line at $45^{\circ}$ illustrates how the NVDF cannot 'daylight' on the lower slope solely by virtue of IP-3 structures. Dashed line conceptually represents either the low-angle thrust or the $10^{\circ}$ foliation measurement by Zwaan et al. (2006), illustrating their potential as low-angle contributors to a complex deformation surface. Subfigures $(C)$ and $(D)$ provide a small drone's view of lineaments ff2 and ff3 looking to the northwest along azimuths as indicated by the Eyes of Horus. Note the general linear, slope-parallel nature of the hummocky, lobate surface bodies in (D). 


\section{Freeze-thaw deformation?}

Nordmannvikdalen exists today within a recently deglaciated, currently periglacial, Arctic and alpine mountain zone. Today's generalized present-day permafrost limit appears to be above the NVDF (Lilleøren et al., 2012). However, during short-lived cold periods between 1275 and 1850 (e.g., the Little Ice Age (LIA); see Matthews \& Briffa, 2005) permafrost may have formed as low as 400 $\mathrm{m}$ ASL within the inner parts of Troms County (Lilleøren et al., 2012). The permafrost line in Nordmannvikdalen probably also migrated downwards by some tens to hundreds of $\mathrm{m}$ in LIA times. Because it is north-facing and receives relatively little sunlight, permafrost conditions may have prevailed somewhat longer in the vicinity of the NVDF than on other slopes.

Common in many arctic and alpine environments, soil creep can be often identified by lobate morphologies (e.g., Matthews et al., 1986; Berthling et al., 2000). Solifluction/gelifluction can also form terraces (e.g., Berthling et al., 2002) or sheets (Matsuoka, 2001; Harris et al., 2011). The non-lobate species remain poorly documented and described. The terrace variety in particular appears to sometimes span several hundreds of meters of length (Zhu, 1996; Wei et al., 2006). In regions that experience many months of snow cover and a short warm season, waterlogged topsoils can be easily mobilized. Some authors have suggested that gelifluction can lead to an increase in the top soil layer (Matthews et al., 1986; Zhu, 1996).

Soil deformation at the permafrost border is a complicated phenomenon that goes well beyond the simple expansion and contraction of soil. For example, it can also include the formation and melt-down of ice lenses (e.g., Matsuoka, 2001; Harris et al., 2011). Laboratory tests indicate that vertical displacement rates can vary widely. Under conditions of seasonal frost penetration but no permafrost, downslope velocity gradients tend to become reduced with depth (Harris et al., 2008). Alternatively, annual thawing of the active layer above perpetually cold permafrost can generate a 'plug-like' displacement of the active layer (op. cit.).

The Kåfjord map quadrangle is littered by symbols marking relict and intact soil-creep landforms (Tolgensbakk \& Sollid, 1988; Lilleøren et al., 2012, fig. 7). Their formation and partial destruction indicates that the upper soil layers have undergone considerable deformation. Because large parts of hillsides above and below the NVDF are covered with solifluction lobes (Fig. 2; Tolgensbakk \& Sollid, 1988), freeze-thaw cycles appear to be very important. Furthermore, the consistent SE to NW decay of the NVDF that tracks the along-strike increase in up-slope dip (Figs. 10,12) and the confinement of the scarp to the topsoil layer (Figs. 13C-E, 14) suggests that a common gravitational process typical of cold region soils at least partly underlies the formation of the scarp.
Unique, but not alone. Tolgensbakk \& Sollid (1988) identified many additional postglacial faults/fissures throughout Kåfjord, including several near the base of the slope below the NVDF and another pair slightly more than $2 \mathrm{k}$ to the northwest of the two boulder deposits (Figs. 2, 16). Although possibly reflecting postglacial expansion cracking, these additional scarp-like features may point equally well to the widespread presence of gravitationally driven processes of freeze-thaw soil deformation.

We focus on a set of neighboring postglacial faults/ fissures (labeled $f f_{1-4}$ ). Whilst all are slope-parallel, these lineaments differ significantly from the NVDF in their geomorphic expressions. Poorly expressed in the landscape as compared to the NVDF itself, $\mathrm{ff}_{4}$ consists of multiple and complicated structures and step-like benches (Fig. 5C-E). Although this lineament group lies to the northwest of the NVDF, it appears unlikely to be the true geologic extension of a fault plane (see above). Nevertheless its surface complexity hints towards some sort of affinity with the subsurface bedrock architecture. Lineament $\mathrm{ff}_{3}$ displays an elongate yet still lobate morphology more reminiscent of the regional solifluction features (Fig. 16D). Like the NVDF, deformation may be confined to the uppermost soil. Unlike it, the $\mathrm{ff}_{3}$ lobes are hummocky and discontinuous, and their scarp faces are neither as steeply dipping nor as sharply defined. Lineament set $\mathrm{ff}_{2}$ is located at the base of the NVDF slope. Many of its constituents are linear to semilinear and have traces of more than $400 \mathrm{~m}$ (Figs. 2, 9). Although sharply defined in some localities they are diffuse in other places, and in general are not as continuous as the NVDF.

The salient points of comparison are that solifluction lobes were mapped by Tolgensbakk \& Sollid (1988) near each lineament set, and also that each lineament set lies adjacent and parallel to a concave or convex topographic break where slope-parallel components of gravitational acceleration undergo large changes over short downslope distances (Figs. 16, 17). Given both Nordmannvikdalen's coastal location and Holocene climate change, we find it quite reasonable to suggest that slope processes typical of cold regions operating before, during, and after LIA permafrost conditions played an important role in shaping the soil profile of these lineaments, especially including the NVDF.

Slope Inflection Point Lineaments? Although all models are wrong, some can be useful (Box \& Draper, 1987). Fig. 17 illustrates one plausible, albeit end-member conceptual example of how soil creep might form a hillside-parallel lineament in the active layer at a topographic break in slope. The model focuses only on frost heaving in winter and surface lowering in summer to produce elongated, relatively linear, non-lobate scarps over a series of freeze-thaw cycles. During freeze-up, the permafrost active layer undergoes slope-perpendicular expansion. An individual particle will travel directly away from (e.g., normal to) the slope (red arrow). During thaw, gravity 

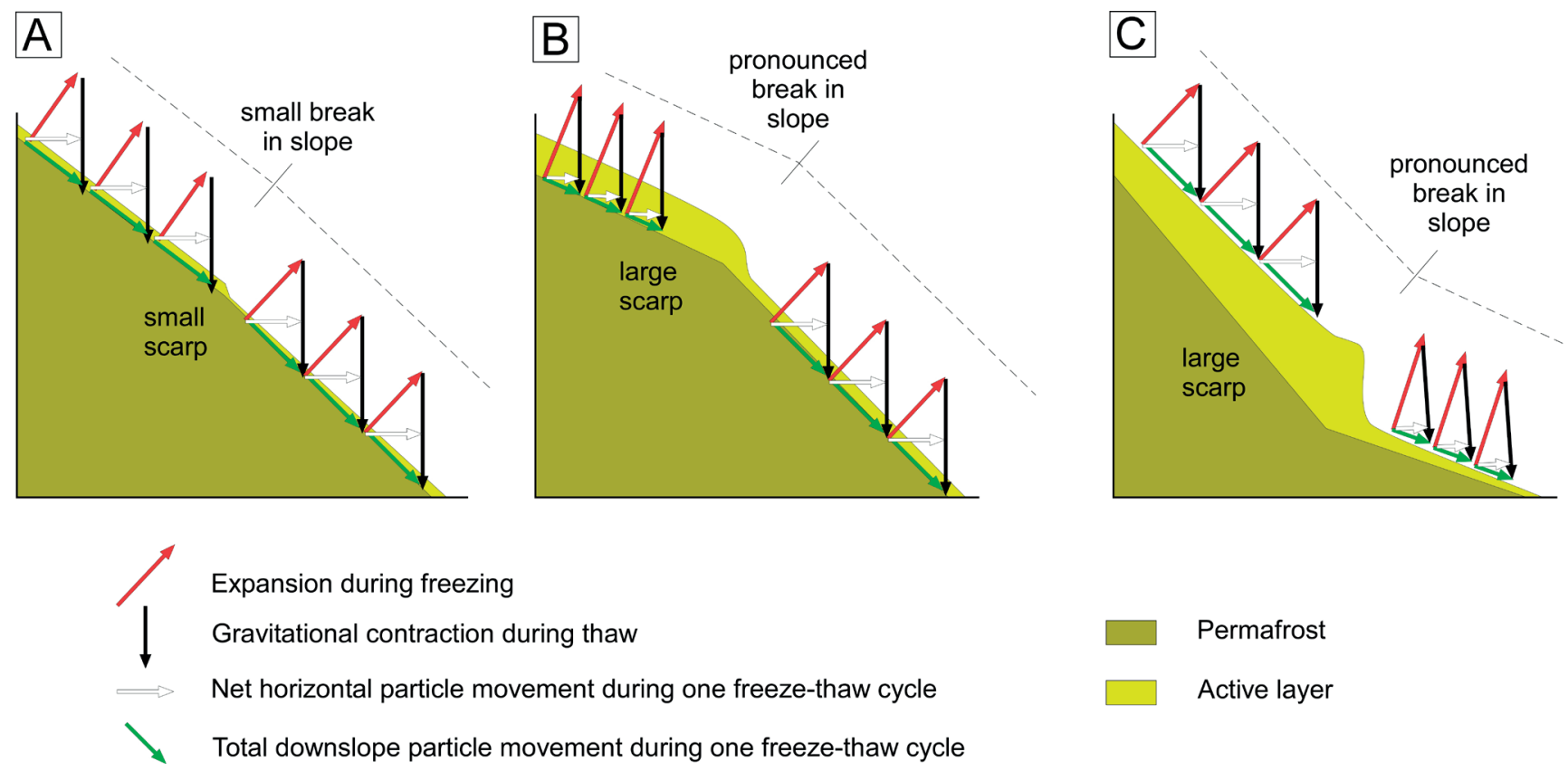

Permafrost

Active layer

Figure 17. Conceptual model for freeze-thaw inflection point lineaments invoking physical expansion and gravitational particle flow during sequential freeze-thaw cycles to generate linear solifluction features. Soil undergoing slope-perpendicular expansion is colored light green. Arrow groupings depict soil cover expansion, contraction, and horizontal/downslope movement during freeze-thaw cycles. At a minimal inflection (A), no significant horizontal transport occurs. Consequently, no slope-parallel gradient of particle flow (green arrows) can develop. At a sharply convex-upward slope break (B), the much greater difference in slope angle above and below the feature causes a slope-parallel gradient of particle flow. This caused the development of and localization of a pronounced scarp. In addition, particle flow reduces the thickness of the active soil layer below a convex break in slope. At concave-upwards slope breaks (C), the inverse velocity difference results in a similar scarp-like feature.

will return the particle exactly on the vertical line (black arrow). Consequently, the freeze-thaw cycle will result in a net downslope flow (green arrow). If the slope angle is constant, particle downslope travel distance will also be constant. However, the travel rate will differ sharply above and below a significant inflection point. Because it will be faster on steeper slopes than on shallow ones, material will be more quickly removed where the lower slope is steeper (e.g., convex), leading to a net thinning of soil. This will cause a scarp-like feature within the upper soil to localize at the break-in-slope. The consistent NW-SE increase in the NVDF scarp height, proxied by shadow width and qualitatively observed in the field by ourselves and Bakken (1983) can thus be related to the flattening of terrain upslope from the scarp in the same direction (Figs. 8, 17A, B). The same process will operate similarly, but inversely, at a concave break in slope (Fig. 17C). Material from upslope will enter the system more rapidly than material downslope can be removed. Extended over a sufficient region, for enough time, this process might create landforms we propose to call SLope Inflection Point (SLIP) lineaments.

An important caveat is that a multiplicity of cold-region processes very likely affected the NVDF site throughout Holocene/Recent time. Many can operate either in tandem or during different climatic conditions. Two in particular - lobate and sheet-flow surface creep, perhaps responding to depth-dependent downslope gradients (e.g., Harris et al., 2008) - may also help produce a thickening of topsoil at convex or concave slope breaks. One possible interpretation could be that the longer wavelength downslope lobes of the scarp (Fig. 7) are relict LIA landforms that stabilized at the break-in-slope, and are currently being overprinted by shorter-wavelength 'modern' lobes.

\section{A time to tear and a time to mend?}

At the end of the day, being able to properly determine the age of the NVDF would impose important constraints upon its nature. However, the data at hand remain inadequate for this task. One problem is that individual components of the NVDF may represent different processes, and therefore by nature be dissimilar in age. As examples, we refer to the crack in the till reported by Bakken (1983) and the $1 \mathrm{~m}$ high scarp near our excavation.

Bakken's interpretation of the crack was as follows: The crack is pre-Recent and may have formed quite early after melting of the ice. It is older than the [boulder deposit] in the west. And also possibly older than moraines in the west: Moraines under Nordmannviktind are thought to have been at their widest extent in the Younger Dryas.

- translated from Bakken (1983) by the authors. 
If our IP-2 unit is hypothesized to constitute the compacted glacial till such as Bakken (1983) reported extending to at least $5 \mathrm{~m}$ depth, the crack clearly postdates it. It must predate the onset of the sediment transport process that mobilized large cobbles and emplaced them into the deeper levels of the crack. If we consider that process to be downslope creep spawned by freeze-thaw cycles, we might surmise the crack was open prior to the LIA. The crack must have persisted as an open feature sufficiently long that its uppermost meter could be filled by organic soil deposits that also incorporated large clasts (Fig. 14; op. cit.). These clasts may have been emplaced after the LIA, permitting the crack to have remained partially open until very recently. This last supposition is supported by the signs of internal drainage still present along its strike (Fig. 8C).

To the southeast in particular the NVDF scarp appears fresh and sharp. The only places it has been significantly eroded are where it is cross-cut by streambed drainages (Figs. 6C, 12). If formed by a one-time event it would need to be old enough that ca. $1 \mathrm{~m}$ of down-cutting could be realized. However, the NVDF scarp appears to follow the contours of the incised river valley as opposed to being truncated by them. In places where the scarp is relatively high, its shadowed trace mimics the many solifluction lobes above and below it (Fig. 6C). We hypothesize that this sector of the NVDF is dominated by SLIP lineament formation and downslope topsoil creep, and as such the scarp is being rejuvenated on a continual and gravitational basis.

\section{Concluding remarks}

Confirming similar field observations by Dehls et al. (2000), our investigations of the bedrock adjacent to the southeastern end of the Nordmannvikdalen feature (NVDF) failed to identify fault rocks. Our shallow excavation into the scarp-like feature at the toe of its slope break did not expose evidence of the colluvial wedge typical of postseismic erosion. Rather, it revealed a continuous soil stratigraphy with no indication of a fault plane, and a scarp made up entirely of topsoil. An earlier excavation (Bakken, 1983) reported an infilled fissure hosted by compacted moraine deposits, but also no fault plane and no offset soil horizons. The well preserved nature of the NVDF indicates that it was not formed by multiple earthquakes with erosional degradation in between each. However, our shadow-proxy analysis shows that the NVDF scarp length and height are inconsistent with empirically derived observed magnitude/length and magnitude/height ratios (e.g., Wells \& Coppersmith, 1994) for normal, reverse, or strike-slip ruptures. Lastly, although Mauring et al. (1998), Dehls et al. (2000) and Olesen et al. $(2000,2004,2013)$ cite their GPR data in support of a recently active fault, line drawing interpretations of their data suggest to us this is not likely. We propose that the hydraulic drawdown hypothesized by Mauring et al. (1997) is instead an imaging of a topographic 'step' at the bedrock-sediment interface. Its absence in the two adjacent GPR profiles lead us to conclude that neotectonic offset of the bedrock surface cannot be resolved at depth. This is particularly so on GPR Profiles 1 and 3, where the surface scarp is nearly $1 \mathrm{~m}$ high yet the trans-NVDF bedrock-sediment contacts are as flat as pancakes. 'Blind' fault rupture over many earthquake cycles did not produce a subsurface monocline. These observational and theoretical constraints indicate to us that the NVDF does not mark a recently active and potentially still-active (e.g., neotectonic) fault. Observing the nomenclature used by Muir Wood (1993), Fenton (1994) and Olesen et al. (2004, 2013), we conclude that the NVDF should be downgraded from its current status as "A (almost certainly neotectonics)" to " $E$ (very unlikely to be neotectonics)." Because Norway's generalized recurrence estimates for medium-large $\left(M_{w} \geq 6.0\right)$ range between a few to several hundred years (Bungum et al., 2005), and large earthquakes are known to trigger rock avalanches (Keefer, 1984), removing the NVDF from the catalogue of Norwegian paleoseismicity has some potential implications for society.

The NVDF surface trace closely follows the intersection of a single, albeit slightly warped plane dipping at some $45^{\circ}$ to the northeast. This plane also matches the trace of the Deep-seated Gravitational Slope Deformation of Kistefjellet (DSGSD-1) and Nordmannviktinden (DSGSD-2). Structures parallel to the nearby low-angle foliation plane and the 'backsliding' thrust fault mapped by Zwaan et al. (2006) render a shallow, composite failure plane plausible. The absence of discernible lateral deformation on the lower slope and the consistent topographic decay of the scarp could indicate that deformation is only beginning to propagate to the northwest of Kistefjellet. However, the shape of the scarp, its confinement entirely to the topsoil layer, the undeformed nature of the underlying inorganic soil, and the absence of a 'step' in bedrock or other traces of gravitational deformation in two out of three Ground Penetrating Radar (GPR) profiles spaced some $50 \mathrm{~m}$ apart renders DSGSD not wholly satisfactory as a solution.

The consistent variation in scarp height in concert with an equally consistent variation in up-scarp hillside steepness points towards of a suite of freeze-thaw slope processes typical of Arctic and alpine environments. As an end-member possibility we have presented a conceptual model of soil lineament formation by particle flow in response to expansion and contraction during freezethaw cycles. However, compared to the entirety of the warmer Holocene, the Little Ice Age (LIA) was a shortlived event that ended only very recently. Significant contributions from other surface slope processes typical of cold regions are certain. But because no slope process is likely to produce a scarp that tracks the surface expression of two adjacent DSGSDs, unless some sort of bed- 
rock structure is there to help to guide it, we are back where we started - possessed by the uncomfortable condition of doubt.

Words, words, words. What is the NVDF, really?

Although not a neotectonic fault, the NVDF remains an important lineament well worthy of future study. It is apparently unique; to our knowledge nothing like it has been reported in the geologic literature. It is probably a composite landform, the summation of several different geologic processes operating across an unknown period of time. The scarp from a Holocene earthquake it is not. Deep-seated Gravitational Slope Deformation (DSGSD) it may possibly be. Downslope topsoil creep in a periglacial climate probably shaped much of the scarp but how all fits together is a masterpiece of confusion. Fair is foul, and foul is fair; forsooth, the last words on Nordmannvikdalen are yet to be written. This is the short and the long of it.

Acknowledgements. Constructive reviews by Alvar Braathen and Ivar Berthling resulted in a greatly improved manuscript. Leif Sørbel kindly provided a valuable description of some of the original fieldwork conducted on the Nordmannvikdalen fault. Slowly but surely our text became a paean to Jon Tolgensbakk and Johan Ludvig Sollid, whose utterly splendid map depicts a very large proportion of that we have discussed, and would appear, for all practical matters, to have originally been drawn at a one-to-one scale. Giulio Viola commented helpfully on a semifinalized version of the manuscript, and Professor Tracy KP Gregg provided a critical clarification that (we hope) circumvented the severe displeasure of the Falcon God. Former NGU employees H.S.S. Bunkholt and J.S. L'Heureaux participated in the fieldwork; their onsite efforts and opinions were instrumental in our suspicion that evidence for neotectonic activity was in absentia in the trench and AWOL on the mountain. TFR acknowledges support from NGU Projects 051242, 051220, and, as always, Project X.

\section{References}

Ahjos, T. \& Uski, M. 1992: Earthquakes in Northern Europe in 13751989, Tectonophysics 207, 1-23. http://dx.doi.org/10.1016/00401951(92)90469-M.

Anda, E., Blikra, L.H. \& Braathen, A. 2002: The Berill Fault - first evidence of neotectonic faulting in southern Norway. Norwegian Journal of Geology 82, 175-182.

Arvidsson, R. 1996: Fennoscandian earthquakes: whole crustal rupturing related to postglacial rebound. Science 274, 744-746. http://dx.doi.org/10.1126/science.274.5288.744.

Bakken, A.J.H. 1983: Nordmannvikdalen kvartaergeologi og geomorfologi. MSc thesis, University of Oslo, $126 \mathrm{pp}$.

Berthling, I., Eiken, T. \& Sollid, J.L. 2000: Continuous measurements of solifluction using carrier-phase differential GPS. Norwegian Journal of Geography 54, 182-185. http://dx.doi. org/10.1080/002919500448558.

Berthling, I., Etzelmüller, B., Larsen, C.K. \& Nordahl, K. 2002: Sediment fluxes from creep processes at Jomfrunut, southern Norway. Norwegian Journal of Geography 56, 67-73. http://dx.doi. org/10.1080/002919502760056378.
Böhme, M., Bunkholt, H.S.S., Oppikofer, T., Dehls, J.F., Hermanns, R.L., Eriksen, H.Ø., Lauknes, T.R. \& Eiken, T. in press: Using 2D InSAR, dGNSS and structural field data to understand the deformation mechanism of the unstable rock slope Gamanjunni 3, northern Norway. Proceedings of 12th International Symposium on Landslides, 12-19 June, Naples, Italy, $7 \mathrm{pp}$.

Box, G.E.P. \& Draper N.R. 1987: Empirical Model-Building and Response Surfaces. John Wiley and Sons, New York, 424 pp.

Bungum, H., Lindholm, C. \& Faleide, J.I. 2005: Postglacial seismicity offshore mid-Norway with emphasis on spatio-temporalmagnitude variations. Marine and Petroleum Geology 22, 137-148. http://dx.doi.org/10.1016/j.marpetgeo.2004.10.007.

Bungum, H., Olesen, O., Pascal, C., Gibbons, S., Lindholm, C. \& Vestol, O. 2010: To what extent is the present seismicity of Norway driven by post-glacial rebound? Journal of the Geological Society of London 167, 373-384. http://dx.doi.org/10.1144/0016-76492009009.

Bunkholt, H.S.S., Osmundsen, P.T., Redfield, T.F., Oppikofer, T., Eiken, T., L'Heureux, J.-S., Hermanns, R.L. \& Lauknes, T.R. 2011: ROS Fjellskred I Troms:status oganalyser etter feltarbeid 2010. Norwegian Geological Survey Report 2011.031, 135 pp.

Bunkholt, H.S.S., Redfield, T.F., Osmundsen, P.T., Oppikofer, T., Hermanns, R.L. \& Dehls, J.D. 2013: The Role of Inherited Structures in Deep Seated Slope Failures in Kåfjorden, Norway. In Margottini, C., Canuti, P. \& Sassa, K. (eds.): Landslide Science and Practice 1. Springer-Verlag Berlin Heidelberg, pp. 265-271. http:// link.springer.com/chapter/10.1007\%2F978-3-642-31325-7_35.

Burbank, D. \& Anderson, R. 2001: Tectonic Geomorphology. Blackwell Publishing, Malden, MA, 274 pp.

Bøe, R., Sørensen, S. \& Hovland, M. 1992: The Karmsundet Basin, SW Norway: stratigraphy, structure, and neotectonic activity. Norwegian Journal of Geology 72, 281-283.

Dawers, N.H., Anders, M.H. \& Scholz, C.H. 1993: Growth of normal faults: Displacement length scaling. Geology 21, 1107-1110. http:// dx.doi.org/10.1130/0091-7613(1993)021<1107:GONFDL>2.3.CO;2.

Dehls, J.F., Olesen, O., Olsen, L. \& Blikra, L.H. 2000: Neotectonic faulting in northern Norway; the Stuoragurra and Nordmannvikdalen postglacial faults. Quaternary Science Reviews 19, 1447-1460. http://dx.doi.org/10.1016/S0277-3791(00)00073-1.

Densmore, A., Dawers, N., Gupta, S., Guidon, R. \& Goldin, T. 2004: Footwall topographic development during continental extension. Journal of Geophysical Research, Earth Surface 109, 6221-6236.

Destro, N. 1995: Release fault: A variety of cross fault in linked extensional fault systems, in the Sergipe-Alagoas Basin, NE Brazil. Journal of Structural Geology, 17, 615-629. http://dx.doi. org/10.1016/0191-8141(94)00088-H.

Fenton, C.H. 1994: Postglacial faulting in eastern Canada. Geological Survey of Canada Open file Report 2774, 98 pp. http://dx.doi. org/10.4095/193973.

Fienan, M.N. 2005: The three-point problem, vector analysis, and extension to the n-point problem. Journal of Geoscience Education, 53, 257-262. http://dx.doi.org/10.5408/1089-9995-53.3.257.

Gudmundsson, A. 1999: Postglacial crustal doming, stresses and fracture deformation with application to Norway. Tectonophysics 307, 407-419. http://dx.doi.org/10.1016/S0040-1951(99)00107-9.

Harris, C., Kern-Luetschg, M., Murton, J., Font, M., Davies, M. \& Smith, F. 2008: Solifluction processes on permafrost and nonpermafrost slopes: results of a large-scale laboratory simulation. Permafrost and Periglacial Processes 19, 359-378. http://dx.doi. org/10.1002/ppp.630.

Harris, C., Kern-Luetschg, M., Christiansen, H.H. \& Smith, F. 2011: The role of interannual climate variability in controlling solifluction processes, Endalen, Svalbard. Permafrost and Periglacial Processes 22, 239-253. http://dx.doi.org/10.1002/ppp.727.

Henderson, I.H.C., Lauknes, T.R., Osmundsen, P.T., Dehls, J., Larsen, Y. \& Redfield, T.F. 2011. A structural, geomorphological and InSAR study of an active rock slope failure development. Geological 
Society of London Special Publications 351, 185-199. http:// sp.lyellcollection.org/content/351/1/185.abstract.

Hendriks, B.W.H., Osmundsen, P.T. \& Redfield, T.F. 2010: Normal faulting and block tilting in Lofoten and Vesterålen constrained by apatite fission track data. Tectonophysics 485, 154-163. http:// dx.doi.org/10.1016/j.tecto.2009.12.011.

Hicks, E., Bungum, H. \& Lindholm, C. 2000: Stress inversions of earthquake focal mechanism solutions from onshore and offshore Norway. Norwegian Journal of Geology 80, 235-250. http://dx.doi. org/10.1080/00291960051030545.

Hovland, M. \& Judd, A.G. 1988: Seabed pockmarks and seepages. Graham \& Trotman, London, 293 pp.

Jarman, D. 2009: Paraglacial rock slope failure as an agent of glacial trough widening: Geological Society of London Special Publications 320, 103-131.http://dx.doi.org/10.1144/SP320.8.

Johannessen, K.C., Kohlmann, F., Ksienzyk, A.K., Dunkl, I. \& Jacobs, J. 2013: Tectonic evolution of the SW Norwegian passive margin based on low temperature thermochronology from the innermost Hardangerfjord area. Norwegian Journal of Geology 93, 243-260.

Keefer, D.K. 1984: Landslides caused by earthquakes. Geological Society of America Bulletin 95, 406-421. http://dx.doi.org/10.1130/00167606(1984)95<406:LCBE>2.0.CO;2.

Keiding, M., Kreemer, C., Lindholm, C.D., Gradmann, S., Olesen, O. \& Kjierulf, H.P. 2015: A comparison of strain rates and seismicity for Fennoscandia: depth dependency of deformation from glacial isostatic adjustment. Geophysical Journal International (Geologische Rundschau) 202, 1021-1028. http://dx.doi.org/10.1093/gji/ggv207.

Kim, Y.S. \& Sanderson, D.J. 2005: The relationship between displacement and length of faults: a review. Earth Science Reviews 68,317-334. http://dx.doi.org/10.1016/j.earscirev.2004.06.003.

Krieger, I., Hermanns, R.L., Schleier, M., Yugsi-Molina, F.X., Oppikofer, T., Rønning, J.S., Eiken, T. \& Rohn, J. 2013: The Berill Fault and its relation to a deep seated gravitational slope deformation (DSGSD). Italian Journal of Engineering Geology and Environment - Book Series (6), 265-273. http://www.ijege.uniroma1.it/rivista/ international-conference-on-vajont-1963-2013-thoughts-andanalyses-after-50-years-since-the-catastrophic-landslide/topic-2predicting-large-landslide-phenomena/the-berill-fault-and-itsrelation-to-a-deep-seated-gravitational-slope-deformation-dsgsd/.

Ksienzyk, A.K., Dunkl, I., Jacobs, J., Fossen, H. \& Kohlmann, F. 2014: From orogen to passive margin: Constraints from fission track and (U-Th)/he analyses on Mesozoic uplift and fault reactivation in SW Norway. In Corfu, F., Gasser, D. \& Chew, D.M. (eds.): New Perspectives on the Caledonides of Scandinavia and Related Areas. Geological Society of London Special Publications 390, pp. 679702. http://dx.doi.org/10.1144/sp390.27.

Lilleøren, K.S., Etzelmüller, B., Schuler, T.V., Gisnås, K. \& Humlum, O. 2012: The relative age of mountain permafrostestimation of Holocene permafrost limits in Norway. Global and Planetary Change 92, 209-223. http://dx.doi.org/10.1016/j. gloplacha.2012.05.016.

Matsuoka, N. 2001: Solifluction rates, processes and landforms: a global review. Earth-Science Reviews 55, 107-134. http://dx.doi. org/10.1016/S0012-8252(01)00057-5.

Matthews, J.A. \& Briffa, K.R. 2005: The 'Little Ice Age': Re-evaluation of an evolving concept. Geografiska Annaler: Series A, Physical Geography 87, 17-36. http://dx.doi.org/10.1111/j.04353676.2005.00242.x

Matthews, J.A., Harris, C. \& Ballantyne, C.K. 1986: Studies on a gelifluction lobe, Jotunheimen, Norway: 14C chronology, stratigraphy, sedimentology and palaeoenvironment. Geografiska Annaler: Series A, Physical Geography 68, 345-360. http://dx.doi. org/10.2307/521526.

Mauring, E., Olesen, O., Rønning, J.S. \& Tønnesen, J.F. 1997: Groundpenetrating radar profiles across post-glacial faults at Kåfjord, Troms, and Fidnajohka, Finnmark. Norges geologiske undersøkelse Report 97.174, $11 \mathrm{pp}$

Mauring, E., Olesen, O., Rønning, J.S. \& Tønnesen, J.F. 1998: Ground
Penetrating Radar profiles across post-glacial faults at Kåfjord, Troms and Fidnajohka, Finnmark. In Dehls, J. \& Olesen, O. (eds.): Neotectonics in Norway. Annual Technical Report 1997, Norges geologiske undersøkelse Report 98.016, pp. 86-92.

McCalpin, J.P. 2009: Paleoseismology in extensional tectonic environments. International Geophysics 95, 171-269. http://dx.doi. org/10.1016/S0074-6142(09)95003-3.

Muir Wood, R. 1989: Extraordinary deglaciation reverse faulting in northern Fennoscandia. In Gregersen, S. \& Basham, P.W. (eds.): Earthquakes at North-Atlantic Passive Margins: Neotectonics and Postglacial Rebound, Kluwer Academic Publishers, Dordrecht, The Netherlands, pp. 141-173. http://dx.doi.org/10.1007/978-94-009-2311-9_10.

Muir Wood, R. 1993: A review of the seismotectonics of Sweden. Swedish Nuclear Fuel and Waste Management Company (SKB) Technical Report 93-13, 225 pp.

Muir Wood, R. 2000. Deglaciation Seismotectonics: a principal influence on intraplate seismogenesis at high latitudes. Quaternary Science Reviews 19, 1399-1411. http://dx.doi.org/10.1016/S02773791(00)00069-X.

Olesen, O. 1988: The Stuoragurra Fault, evidence of neotectonics in the Precambriqan of Finnmark, northern Norway. Norwegian Journal of Geology 68, 107-118.

Olesen, O. \& Dehls, J.F. 1998: Classification and quality assessment of reported Neotectonic phenomenon (Task 1). In Dehls, J.F. \& Olesen, O. (eds.): Neotectonics in Norway. Annual Technical Report 1997, Norges geologiske undersøkelse Report 98.016, pp. 3-30.

Olesen, O., Gjelle, S., Henkel, H., Karlsen, T.A., Olsen, L. \& Skogseth, T. 1994: Neotectonic studies in the Ranafjorden area, northern Norway. Norges geologiske undersøkelse Report 94.073, 42 pp.

Olesen, O., Dehls, J., Bungum, H., Riis, F., Hicks, E., Lindholm, C., Blikra, L.H., Fjeldskaar, W., Olsen, L., Longva, O., Faleide, J.I., Bockmann, L., Rise, L., Roberts, D., Braathen, A. \& Brekke, H. 2000: Neotectonics in Norway, Final Report. Norges geologiske undersøkelse Report 2000.002, 135 pp.

Olesen, O., Blikra, L.H., Braathen, A., Dehls, J.F., Olsen, L., Rise, L., Roberts, D., Riis, F., Faleide, J.I. \& Anda, E. 2004: Neotectonic deformation in Norway and its implications: a review. Norwegian Journal of Geology 84, 3-34.

Olesen, O., Bungum, H., Dehls, J., Lindholm, C., Pascal, C. \& Roberts, D. 2013: Neotectonics, seismicity and contemporary stress field in Norway - mechanisms and implications. In Olsen, L., Fredin, O. \& Olesen, O. (eds.): Quaternary Geology of Norway, Geological Survey of Norway Special Publication 13, pp. 145-174.

Osmundsen, P.T. \& Redfield, T. 2011: Crustal taper and topography at passive continental margins. Terra Nova 23, 1-13. http://dx.doi. org/10.1111/j.1365-3121.2011.01014.x.

Osmundsen, P.T., Henderson, I., Lauknes, T.R., Larsen, Y., Redfield, T.F. \& Dehls, J. 2009: Tectonic controls on topography and masswasting processes in Northern Norway. Geology 37, 135-138. http://dx.doi.org/10.1130/G25208A.1.

Osmundsen, P.T., Redfield, T.F., Anda, E., Hendriks, B.W.H., Henderson, I., Dehls, J., Lauknes, T.R., Fredin, O. \& Davidsen, B. 2010: The tectonic significance of Alpine landscapes in Norway. Journal of the Geological Society of London 167, 83-98. http:// dx.doi.org/10.1144/0016-76492009-019.

Plassen, L. \& Vorren, T.O. 2003: Fluid flow features in fjord-fill deposits, Ullsfjorden, North Norway. Norwegian Journal of Geology $83,37-42$.

Redfield, T.F. \& Osmundsen, P.T. 2009: The Tjellefonna fault system of Western Norway: Linking late-Caledonian extension, postCaledonian normal faulting, and Tertiary rock column uplift with the landslide-generated tsunami event of 1756 . Tectonophysics 474, 106-123. http://dx.doi.org/10.1016/j.tecto.2009.02.006.

Redfield, T.F. \& Osmundsen, P.T. 2013: The long-term topographic response of a continent adjacent to a hyperextended margin: A case study from Scandinavia. Geological Society of America Bulletin 125, 184-200. http://dx.doi.org/10.1130/B30691.1.

Redfield, T.F. \& Osmundsen, P.T. 2015: Some remarks on the 
earthquakes of Fennoscandia: A conceptual seismological model drawn from the perspectives of hyperextension. Norwegian Journal of Geology 94, 233-262. http://dx.doi.org/10.17850/njg94-4-01.

Redfield, T.F., Osmundsen, P.T. \& Hendriks, B.W.H. 2005: The role of fault reactivation and growth in the uplift of western Fennoscandia. Journal of the Geological Society of London 162, 1013-1030. http://dx.doi.org/10.1144/0016-764904-149.

Rise, L., Ottesen, D., Berg, K. \& Lundin, E. 2005: Large-scale development of the mid-Norwegian margin during the last 3 million years. Marine and Petroleum Geology 22, 33-44. http:// dx.doi.org/10.1016/j.marpetgeo.2004.10.010.

Schleier, M., Hermanns, R.L., Krieger, I., Oppikofer, T., Eiken, T., Rønning, J.S. \& Rohn, J. 2016: Gravitational reactivation of a pre-existing post-Caledonian fault system: the deep-seated gravitational slope deformation at Middagstinden, western Norway. Norwegian Journal of Geology 96, 201-222. http://dx.doi. org/10.17850/njg96-3-03.

Sigmond, E.M.O. 1992. Bedrock map of Norway and adjacent ocean areas, scale 1:3,000,000, Norges geologiske undersøkelse.

Steno, N. 1669: The Prodromus of Nicolaus Steno's Dissertation concerning a solid body enclosed by process of nature within a solid; an English version with an introduction and explanatory notes by John Garrett Winter. Macmillan Company (1916), New York, 283 pp. http://dx.doi.org/10.5962/bhl.title.54340.

Stewart, I.S., Sauber, J. \& Rose, J. 2000: Glacio-seismotectonics: ice sheets, crustal deformation and seismicity. Quaternary Science Reviews 19, 1367-1389. http://dx.doi.org/10.1016/S02773791(00)00094-9.

Sutinen, R., Hyvönen, E., Middleton, M. \& Ruskeeniemi, T. 2014: Airborne LiDAR detection of postglacial faults and Pulju moraine in Palojärvi, Finnish Lapland. Global and Planetary Change 115, 24-32. http://dx.doi.org/10.1016/j.gloplacha.2014.01.007.

Tolgensbakk, J. \& Sollid, J.L. 1988: Kåfjord, kvartvrgeologi og geomorfologi 1634 II, scale 1:50,000, Geografisk institutt, University of Oslo.

Wei, M., Fujun, N., Satoshi, A. \& Dewu, J. 2006: Slope instability phenomena in permafrost regions of Qinghai-Tibet Plateau, China. Landslides 3, 260-264. http://dx.doi.org/10.1007/s10346-006-0045-0.

Wells, D.L. \& Coppersmith, K.J. 1994: Empirical relationships among magnitude, rupture length, rupture area, and surface displacement. Bulletin of the Seismological Society of America 84, 974-1002.

Wu, P. \& Hasagawa, H.S. 1996: Induced stresses and fault potential in eastern Canada due to a disc load: a preliminary analysis. Geophysical Journal International (Geologische Rundschau) 125, 415-430. http://dx.doi.org/10.1111/j.1365-246X.1996.tb00008.x.

Zhu, C. 1996: Rates of periglacial processes in the Central Tianshan, China. Permafrost and Periglacial Processes 7, 79-94. http:// dx.doi.org/10.1002/(SICI) 1099-1530(199601)7:1<79::AID PPP208>3.0.CO;2-O.

Zwaan, K.B., Dangla, P. \& Quenardel, J.M. 2006: Bergrunnskart Kåfjord 1634 II, scale 1:50,000, Norges geologiske undersøkelse. 